HERRERA, Mercedes. "La negociación en el proceso penal desde la dogmática del

Derecho penal. Especial referencia a los ordenamientos español y peruano".

Polít. crim. Vol. 11, No 21 (Julio 2016), Art. 9, pp. 229-263.

[http://www.politicacriminal.cl/Vol_11/n_21/Vol11N21A9.pdf]

\title{
La negociación en el proceso penal desde la dogmática del Derecho penal. Especial referencia a los ordenamientos español y peruano
}

\section{Negotiation in a penal process from the dogmatic of Criminal law. Special reference to the Spanish and Peruvian legal systems.}

\author{
Mercedes Herrera ${ }^{1}$ \\ Doctora en Derecho por la Universidad de Navarra. \\ Profesora de Derecho penal y Derecho procesal penal en la Universidad de Piura. \\ mercedes.herrera@udep.pe
}

\section{Resumen}

El presente artículo trata sobre la incidencia de la negociación en el proceso penal en la eficacia preventivo-general de la pena y la protección de bienes jurídicos como función del Derecho penal. Tras un análisis sistemático se advierte la necesidad de excluir la negociación en los delitos graves, es decir, de aquellos en los que la modificación de las consecuencias jurídicas mediante criterios ajenos a la norma de conducta afecte significativamente la prevención general y la comunicación acerca del valor del bien jurídico protegido. Así pues, se propone una doble vía procesal: mantener el juicio oral en los delitos graves y permitir la negociación en los delitos leves. Esta propuesta se refiere especialmente a la actual regulación de la negociación en los procesos penales español y peruano, respecto a los cuales se formulan algunas consideraciones de lege ferenda.

Palabras clave: Negociación procesal, conformidad, justicia penal negociada, terminación anticipada del proceso, sistema de justicia penal, sistema integral de Derecho Penal.

\begin{abstract}
This paper discusses how negotiations in criminal proceedings affect the preventive-general effectiveness of punishment and the protection of legal goods as a function of Criminal law. After a systematic analysis, the need appears to exclude negotiations in felonies, that is, those in which the amendment of legal consequences through criteria foreign to the sanctioned conduct materially affects general prevention and communication regarding the value of the protected legal good. Thus, a double procedural way is proposed: maintain an oral trial for felonies and allow negotiation for misdemeanors. This proposal especially

\footnotetext{
${ }^{1}$ Este trabajo corresponde parcialmente a la tesis doctoral de la autora "Aproximación a la justicia penal negociada en los ordenamientos español y peruano desde una perspectiva integral. Un estudio procesal y sustantivo desde un enfoque comparativo", defendida en la Universidad de Navarra el 7 de noviembre de 2013, el mismo que ha sido publicado con el título: La negociación en el nuevo proceso penal. Un análisis comparado. Palestra, Lima, 2014.
} 
HERRERA, Mercedes. "La negociación en el proceso penal desde la dogmática del Derecho penal. Especial referencia a los ordenamientos español y peruano".

refers to current negotiation regulation in the Spanish and Peruvian criminal proceedings, for which some lege ferenda factors are proposed.

Key words: Procedural negotiation, consent, negotiated criminal justice, early termination fee, criminal justice system, integrated system of criminal law.

\section{Introducción}

El tema de la negociación en el proceso penal es actualmente un tópico común en los estudios de Derecho procesal penal. En países de habla hispana ha sido objeto de atención casi exclusivamente por parte de los procesalistas, quienes, como parece natural, han efectuado un análisis crítico fundamentalmente desde el prisma del Derecho procesal. Al mismo tiempo, la relación entre los acuerdos en el proceso penal y el Derecho penal sustantivo es un tema del que los especialistas en Derecho penal apenas se han ocupado.

No resulta fácil encontrar una justificación conceptual de los acuerdos en sí mismos en la medida que implican negociar con el ius puniendi. En cualquier caso, se trata de una legitimación o intento de justificación ex-post. Ello obliga a la doctrina a construir un sistema conceptual nuevo que reemplace al anterior o uno paralelo que justifique la doble vía procedimental (juicio oral y negociación en el proceso penal). Sin embargo, no puede negarse que actualmente las críticas contra este fenómeno (también las que se formulan en este trabajo) chocan contra el muro inexpugnable de la realidad: varios ordenamientos contemplan la negociación en el proceso penal.

Sin perjuicio de reconocer otros fines, se debe enfatizar que el Derecho procesal penal sirve en primer lugar a la aplicación del Derecho penal, es decir, al mantenimiento de la vigencia de la norma de sanción. En este sentido, el Derecho penal material será eficaz en la medida en que se realice a través del proceso, lo que implica que el proceso penal se oriente por lo dispuesto por el Derecho penal material ${ }^{2}$.

En la negociación en el proceso penal se deja de lado la certeza como condición de determinación del delito y de su relación con el acusado, porque se abandona el principio de investigación de la verdad material y se admite que en el marco de la negociación en el proceso penal basta una verdad formal o "verdad consensual".

Tanto en la conformidad negociada como en la terminación anticipada la certeza se sustituye por la probabilidad de la comisión del delito por el imputado. En realidad, el Juez ya no realiza una actividad cognoscitiva directa, no evalúa en primer término los elementos de convicción introducidos en el proceso; sino el acuerdo entre la acusación y el imputado, que, como es lógico, limita de modo significativo el ámbito de su función en relación a la prueba.

Si se compara el proceso civil con el penal en el plano de la prueba, se advierte que en el primero, aunque también se busca la verdad en el proceso, éste tiene como fin principal

\footnotetext{
${ }^{2}$ ROXIN, Claus; SCHÜNEMANN, Bernd, Strafverfahrensrecht. 27ª ed., Munich: Beck, 2012, pp. 73 y ss.
} 
Polít. crim. Vol. 11, No 21 (Julio 2016), Art. 9, pp. 229-263.

[http://www.politicacriminal.cl/Vol_11/n_21/Vol11N21A9.pdf]

tutelar los derechos de las partes, quienes determinan tanto el objeto del proceso, como por regla general- establecen los medios de prueba que han de actuarse ${ }^{3}$. En el proceso penal, en cambio, la determinación cierta de los hechos con apariencia de delito tiene un carácter esencial.

Asimismo, la presunción de inocencia tiene relación directa con la culpabilidad como elemento del tipo penal que, como corresponde al proceso penal propio de un Estado de Derecho y a la relación entre lo sustantivo y lo procesal, debe ser probado ${ }^{4}$. Sobre este punto, cabe recordar que la búsqueda de la verdad material en el proceso penal permite la realización del Derecho penal sustantivo, es decir la determinación cierta de que el acusado ha realizado una acción antijurídica y culpable ${ }^{5}$. Este principio tiene su fundamento último en la dignidad humana, en el principio de culpabilidad y en el Estado de Derecho que exigen que la pena impuesta sea el resultado de un proceso que ofrezca suficientes garantías para encontrar la verdad material ${ }^{6}$.

Puesto que, en la negociación en el proceso penal se prescinde de la prueba, surge también la siguiente cuestión: si al Derecho penal le interesa que se verifiquen con pruebas suficientes los elementos del delito y la intervención del imputado en el mismo, en la negociación en el proceso penal se produce una atenuación de este interés.

Las instituciones de la negociación en el proceso penal suponen una renuncia a uno de los fines más importantes del Derecho procesal penal: la búsqueda de la verdad material como conditio sine qua non para desvirtuar la presunción de inocencia y emitir una sentencia condenatoria; y al mismo tiempo, modifica su carácter instrumental respecto al Derecho penal. De este modo, se pierde la herencia que se introdujo en el siglo XIX: el juicio oral como estructura contradictoria idónea para encontrar la verdad y por tanto, para determinar de modo legítimo la culpabilidad del acusado ${ }^{7}$.

\section{La ausencia de un análisis jurídico-penal de la negociación en el proceso penal.}

El fenómeno de la negociación en el proceso penal se ha extendido en un gran número de países del sistema continental europeo, no sólo en Latinoamérica, sino también en Europa. Incluso en Alemania, el país donde el Derecho penal como disciplina científica ha nacido y se ha desarrollado con mayor profundidad y extensión, esta figura se aplica en muchos casos con menos garantías que en otros países en donde está vigente esta institución ${ }^{8}$, y

\footnotetext{
${ }^{3}$ MONTERO AROCA, Juan, La prueba en el proceso civil, $5^{\text {a }}$ ed. Pamplona: Aranzadi, 2007, pp. 47 y ss.

${ }^{4}$ STC español 34/1996, de 11 de marzo y STC 123/ 1997, de 1 de julio.

${ }^{5}$ SCHÜNEMANN, Bernd, „Die Hauptverhandlung im Strafverfahren. Was sie leistet, wo sie versagt und in welcher Form sie bewahrt werden muss“, Strafverteidiger forum, 2010, p. 91.

${ }^{6}$ SCHÜNEMANN, Bernd, ,Reformaspekte des strafrechtlichen Haupt-und Rechtsmittelsverfahrens“, en: Die Reform des Haupt-und Rechtsmittelverfahrens. RichterInnenwoche 2010 in Geinberg 17.21 Mai 2010, WienGraz: Bundesministerium fürJustiz, 2011, p. 18.

${ }^{7}$ SCHÜNEMANN, Bernd, „Zur Kritik des amerikanischen Strafprozessmodells“. En: FS für Gerhard Fezer zum 70. Geburstag am 29, Oktober 2008. Berlin: De Gruyter Recht, 2008, pp. 564 y ss.

${ }^{8}$ Sobre algunos problemas en la práctica de la negociación en el proceso penal alemán, el Tribunal Constitucional de ese país se ha pronunciado recientemente en la Sentencia de 19 de marzo de 2013. BVerfG, 2 BvR 2628/10 vom 19.3.2013, Absatz-Nr. (1 - 132), http://www.bverfg.de/entscheidungen/rs20130319_2bvr262810.html
} 
HERRERA, Mercedes. "La negociación en el proceso penal desde la dogmática del Derecho penal. Especial referencia a los ordenamientos español y peruano".

puede ser calificada en la práctica, tal como afirma Bernd Schünemann ${ }^{9}$, como el ocaso de la cultura jurídico-penal alemana.

De acuerdo con un estudio empírico realizado entre los años 2004 y 2006 por un grupo de expertos de la universidad Heinrich-Heine en Düsseldorf en el ámbito de la negociación en el proceso penal en delitos económicos ${ }^{10}$, la carga procesal no es el principal motivo por el cual el Juez, el Fiscal y los abogados participan en tales acuerdos. Para muchos de ellos esta figura (que entonces no estaba prevista legalmente) es, sobre todo, una vía rápida y eficaz para poner fin al proceso. Con base en este estudio se ha afirmado, que este fenómeno no sólo es producto de una real y supuesta sobrecarga procesal, sino también de la comodidad y pereza de quienes participan en esos acuerdos (jueces, fiscales y abogados defensores) ${ }^{11}$.

A pesar de las críticas que han suscitado la negociación en el proceso penal alemán, también se admite, con cierta resignación, que frente al ingente volumen de procesos ésta se ha convertido en imprescindible para el funcionamiento de la justicia ${ }^{12}$.

Tampoco ha existido en Alemania un trabajo conjunto entre las disciplinas de Derecho constitucional, Derecho de policía y Derecho procesal penal. No ha habido comisión alguna que disponga el trabajo conjunto de científicos y actores del Derecho para una reforma integral del Derecho procesal penal. De esta forma, se ha cambiado el núcleo del proceso penal sin ningún estudio previo y sin fundamentos teóricos suficientes sobre la política procesal penal perseguida ${ }^{13}$.

Si bien se presentan problemas de naturaleza procesal, las cuestiones más profundas que suscitan las instituciones de la negociación en el proceso penal se remiten al ámbito del Derecho penal material, ya que a través de la negociación en el proceso penal se atenúan los criterios de imputación y, al mismo tiempo, se renuncia parcialmente a una imputación formalizada $^{14}$.

En el contexto de la negociación en el proceso penal se puede establecer una relación entre la Dogmática penal y procesal penal a través de la siguiente figura: La primera se presenta como la cabeza de un niño encefálico y raquítico desproporcionadamente grande. Por ello, el pobre cuerpo pequeño y escuálido (ahora me refiero también a las normas procesales penales y al proceso penal en concreto) no es capaz de sostener un sistema de estas

\footnotetext{
${ }^{9}$ SCHÜNEMANN, „Zur Kritik des amerikanischen“, cit nota n ${ }^{\circ}$ 7, p. 571.

${ }^{10}$ ALTENHEIN, Karsten; HAGEMEIER, Ina; HAIMERL, Michael; STAMMEN, Karl-Heinz, Die Praxis der Absprachen in Wirtschaftsstrafverfahren. Düsseldorf: Nomos, p. 331.

11 GÖSSEL, Karl Heinz, „Quo Vadis, Strafverfahren? Zweckmäßigkeit versus Gerechtigkeit: Vom rechtsstaatlichen Strafprozess zum geheimen Willkürverfahren in der babylonischen Gefangenschaft der justiz“, Festeschrift für Gerhard Fezer zum 70 (2008), p. 499.

${ }_{12}^{12}$ KINDHÄUSER, Urs, Strafprozessrecht. $2^{\mathrm{a}}$ ed., Baden- Baden: Nomos, 2010, pp. 212 y ss.

${ }^{13}$ WOLTER, Jürgen, „Zur Theorie und Systematik des Strafprozessrechts. Nachschau und Ausblick“, en: WOLTER, Jürgen (Ed.), Zur Theorie und Systematik des Strafprozessrechts.Symposium zu Ehren von HansJoachim Rudolphi. Dortmund: Luchterhand, 1995, p. 268.

14 HASSEMER, Winfried, „Prolegomena einer Lehre von der Zurechung“, en: SCHULZ, Joachim; VORMBAUM, Thomas (Eds.), FS für Günther Bemmann, Baden-Baden: Nomos, 1997, p. 187.
} 
Polít. crim. Vol. 11, No 21 (Julio 2016), Art. 9, pp. 229-263.

[http://www.politicacriminal.cl/Vol_11/n_21/Vol11N21A9.pdf]

características. Esta situación se hace aún más patente cuando se observa la separación entre las normas, la doctrina procesal y la práctica.

Con la negociación en el proceso penal se abren las puertas a criterios distintos a los establecidos por el Derecho penal positivo, y en este sentido se modifican las consecuencias jurídicas previstas en los tipos penales concretos. Ante esta circunstancia, surge la pregunta acerca de la legitimación de estos cambios y de los efectos de este "nuevo marco jurídicopenal" desde una perspectiva material, teniendo en cuenta, la función que cumple el Derecho penal sustantivo y el carácter instrumental del Derecho procesal penal.

En las siguientes páginas analizaré algunos aspectos en los que se materializa el carácter instrumental del Derecho procesal penal en la negociación en el proceso penal en dos puntos concretos que se encuentran estrechamente relacionados: la protección del bien jurídico como función del Derecho penal y la prevención general como fin de la pena.

Un análisis en esta línea ha sido llevado a cabo por la doctrina con respecto a otras instituciones procesales; por ejemplo con el principio de oportunidad ${ }^{15}$, la reparación de daños (Schadenswiedergutmachung) y la conciliación entre víctima y autor (Täter-Opfer Ausgleich $)^{16}$.

En España ${ }^{17}$, y también en alguna medida en Perú $^{18}$, el proceso penal y sus instituciones se analizan casi siempre sólo desde una perspectiva meramente procesal. Así por ejemplo,

\footnotetext{
${ }^{15}$ Sobre el principio de oportunidad y sus efectos en el Derecho penal material Wolfgang Naucke señala que con esta figura la eficacia del Derecho procesal sobre el Derecho material llega lejos en la medida que se altera el concepto de delito y con ello se afectan los esfuerzos de la doctrina por limitar el tipo penal en cuestión (por ejemplo el tipo de hurto). Asimismo, este autor pone énfasis en que se prescinde de la fundamentación y se pronuncia la sentencia sin necesidad de fundamentar la decisión porque se acude únicamente a los criterios de conveniencia u oportunidad. NAUCKE, Wolfgang, Die Wechselwirkung zwischen Strafziel und Verbrechensbegriff, Stuttgart: Franz Steiner, 1985, p. 170. Otros trabajos sobre el principio de oportunidad en Alemania: POTT, Christine, Die Außerkraftsetzung der Legalitäts durch das Opportunitätsdenken in den Vorschriften der a StPO. Zugleich ein Beitrag zu einer kritischen Strafverfahrensrechtstheorie. Frankfurt am Main: Peter Lang, 1996, p. 184; DEITERS, Mark, Legalitätsprinzip und Normgeltung. Tübingen:Mohr Siebeck, 2006, p. 314; ERB, Volker, Legalität und Opportunität.Gegensätzliche Prinzipien der Andwendung von Strafrechtsnormen im Spiegel rechtstheoretischer, rechtsstaatlicher und rechtspolitischer Überlegungen, Berlin: Duncker \& Humblot, 1999.

${ }^{16}$ Sobre la reparación de daños y la conciliación entre víctima y autor se afirma que cumplen funciones de prevención especial, pero también de prevención general sobre todo en la variante de integración-prevención, así la satisfacción de la víctima con la solución del conflicto puede verse como un aspecto de integración y por regla general también tendrá influencia en la generalidad. KASPAR, Johannes, Wiedergutmachung und Mediation im Strafrecht. Rechtliche Grundlagen und Ergebnisse eines Modellprojekzs zur anwaltichen Schlichtung. Münster: Lid, 2004, p. 309. También, KESPE, HansChristian, Täter-Opfer-Ausgleich und Schadenswiedergutmachung. Ein Beitrag zur Dogmatik von $\$ 46^{a}$ StGB unter besonderer Berücksichtigung steuerstrafrechtlicher Fragestellungen. Berlín: Duncker \& Humblot, 2011, pp. 307 y ss.; JUNG, Cornelia, Der Täter-Opfer-Ausgleich als Weisung. Verfahrensrechtliche Einwände und Auswege im Hinblick auf \$153 a. Abs. 1 StPO. Hamburg: Dr. Kovač, 2008, p. 364.

${ }^{17}$ En España son los estudiosos de Derecho procesal los que se ocupan del Derecho procesal penal. En cambio los especialistas de Derecho penal en su gran mayoría centran el objeto de sus estudios en la dogmática jurídico-penal y en muy pocas ocasiones dirigen su atención hacia temas procesales o en ocasiones lo hacen pero sólo de forma marginal. En Alemania en cambio hay una unidad sistemática en el tratamiento
} 
HERRERA, Mercedes. "La negociación en el proceso penal desde la dogmática del Derecho penal. Especial referencia a los ordenamientos español y peruano".

cuando la FGE considera la conformidad como una expresión del desarrollo de la propia personalidad y, en concreto, manifestación de la autonomía de la voluntad del acusado ${ }^{19}$, o cuando el TS postula que la manifestación de voluntad del acusado exime a las partes de la práctica de la prueba, se olvida la diferencia fundamental entre el proceso civil y penal ${ }^{20}$ : que en este último no rige el principio de disposición (como si rige en el proceso civil como consecuencia del principio de autonomía de las partes) y en este sentido, la norma jurídicopenal tiene un carácter imperativo, a diferencia del ámbito civil donde sí se puede hablar en sentido propio de consenso ${ }^{21}$.

Asimismo, de acuerdo con nuestra tradición procesal penal continental, el consenso o la aceptación del acusado no proporciona un fundamento suficiente de imputación y la confesión sólo constituye un indicador suficiente de imputabilidad cuando concurren otras pruebas y es fiable ${ }^{22}$. Más aún, la propia naturaleza de la pena que expresa un reproche moral y tiene consecuencias negativas en la vida social del condenado, excluye que se pueda imponer sólo con base en la voluntad o deseo del acusado de recibir esa pena ${ }^{23}$ (y esto incluye la "expresión del desarrollo de la propia personalidad").

A mi juicio, desde un análisis procesal de la negociación en el proceso penal se pone énfasis, sobre todo, en los derechos y garantías del acusado, que se ven afectados con esta institución procesal; así como la modificación de los roles de las partes que intervienen a lo largo del procedimiento de negociación y de la función del Juez. Mientras que, desde el Derecho penal, se puede ver cómo afecta la negociación en el proceso penal a la función del Derecho penal sustantivo (la protección de bienes jurídicos) y en la prevención general como fin de la pena; es decir, cómo incide esta institución en el carácter público del delito y en el fundamento de la intervención estatal, cuestionándolo. Este análisis sustantivo no se

de cuestiones de índole procesal penal, porque muchos especialistas en Derecho penal también se ocupan del proceso penal, lo que facilita la coherencia y articulación entre estas dos ramas del Derecho. A título de ejemplo se pueden citar: HASSEMER, Winfried, Einführung in die Grundlagen des Strafrechts, $2^{\mathrm{a}}$ edición, Múnich: C.H Beck, 1990, pp. 115 y ss. Asimismo, los manuales de Derecho procesal penal escritos por especialistas en Derecho penal para complementar la exposición sobre el Derecho penal material. KINDHÄUSER, Strafprozessrecht, cit. nota $n^{\circ} 12$; ROXIN/SCHÜNEMANN, Strafverfahrensrech, cit. nota $\mathrm{n}^{\circ}$ 2. Lo mismo ocurre en Italia.

${ }^{18}$ La Dogmática procesal penal en nuestro país es aún incipiente.

${ }^{19}$ Circular 1/1989, de 8 de marzo de la FGE.

${ }^{20}$ En los últimos años se ha producido un acercamiento entre los procesos civil y penal, sobre todo en el ámbito de los principios, lo que implica una atenuación de las fronteras, antaño claras, entre lo público y lo privado. Sobre este tema: ARMENTA DEU, Teresa (Coord.), La convergencia entre proceso civil y penal ¿una dirección adecuada?, Madrid: Marcial Pons, 2013, p. 260. También OLIVA SANTOS, Andrés de, El papel del Juez en el proceso civil. Frente a ideología, prudentia iuris. Pamplona: Thomson Reuters, 2012, pp. 25 y ss.

21 SCHÜNEMANN, Bernd, "Konsens im Strafverfahren-Performativer Selbstwiderspruch, Chimäre oder konkrete Utopie?” en: POSCH, Willibald; SCHLEIFER, Wolfgang; FERZ, Sascha (Eds.), Konfliktlösung im Konsens: Schiedgerichtsbarkeit, Diversion, Mediation. 7. Fakultätstag der Rehctswissenschaftlichen Fakultät der Karl-Franzes-Universität Graz, Graz: Leykam, 2010, p. 55.

22 HASSEMER, "Prolegomena", cit. nota $\mathrm{n}^{\circ}$ 14; SCHÜNEMANN, Bernd,"Wohin treibt der deutsche Strafprozess?", ZStW 114 (2002), pp. 60 y ss.

${ }^{23}$ SCHÜNEMANN, ,Zur Kritik des amerikanischen“, cit nota ${ }^{\circ} 7$. 
Polít. crim. Vol. 11, No 21 (Julio 2016), Art. 9, pp. 229-263.

[http://www.politicacriminal.cl/Vol_11/n_21/Vol11N21A9.pdf]

centra en el acusado ${ }^{24}$, sino en los intereses que se protegen con el ius puniendi (los bienes jurídicos). Al mismo tiempo, cuando se trata la neutralización de la función que cumple el Derecho penal, se advierte que dentro del Derecho penal existen distintas "cualidades" de delitos, situación que se ha agravado con la modernización del Derecho penal.

La relación entre los distintos niveles: faltas, conductas que son susceptibles de ser despenalizadas, delitos en los que es aplicable el principio de oportunidad, delitos leves en los que se pueden admitir formas de conclusión anticipada del proceso, conformidad o terminación anticipada no puede ser analizada -como sucede hasta ahora con la negociación en el proceso penal- sólo desde una perspectiva procesal. Si bien en este ámbito se pueden proponer importantes mecanismos para corregir los posibles abusos en el marco de la negociación en el proceso penal, no se resuelve con ello el problema de fondo ${ }^{25}$.

En algunas ocasiones parece que la doctrina penal no advierte que sin el proceso penal, o sin un proceso penal adecuado y justo no es posible que el Derecho penal cumpla la función de proteger bienes jurídicos ${ }^{26}$. En este sentido, un análisis crítico de este fenómeno no puede limitarse sólo desde la conveniencia o utilidad procesal, toda vez que, éste incide en el Derecho penal sustantivo y en su estructura normativa ${ }^{27}$.

Un estudio sistemático de la negociación en el proceso penal puede proporcionar luces nuevas en el análisis de esta institución, ya que la misma despliega sus efectos no sólo en el proceso penal sino sobre todo el sistema jurídico-penal. Pero además, en ningún ámbito se plantea actualmente con tanta urgencia la necesidad de que la ciencia jurídico penal (que comprende también a la procesal) y la práctica se tomen en serio mutuamente ${ }^{28}$.

Desde mi perspectiva, sólo a partir de un análisis sistemático de instituciones como la negociación en el proceso penal es posible alcanzar una armonía en las ciencias jurídicos penales que repercute no en la "belleza artística del sistema", sino que incide fundamentalmente en la eficiencia y el buen funcionamiento de la justicia penal. Aquí se vuelve a plantear la cuestión de la "ciencia global del Derecho penal" (gesamte Strafrechtswissenschaft $)^{29}$ o el tema del delito, la medida de la pena y el proceso penal en el

\footnotetext{
${ }^{24}$ Es posible tratar esta relación también desde la perspectiva del acusado si se considera por ejemplo el principio de culpabilidad y sus exigencias en el proceso penal. Pero esta relación puede reconducirse en última instancia al ámbito procesal a través de la presunción de inocencia.

${ }^{25}$ En esta línea, LÜDERSSEN, Klaus, Abschaffen des Strafens?. Frankfurt am Main: Suhrkamp, 1995, p. 329.

${ }^{26}$ HASSEMER, Einführung in die Grundlagen des Strafrechts, cit. nota n ${ }^{\circ} 17$, p. 110.

${ }^{27}$ SCHÜNEMANN, Bernd, Vom Tempel zum Marktplatz. Múnich: C.H. Beck, 2013.

${ }^{28}$ BÖTTSCHER, Reinhard, „Der deutsche Juristentag und die Absprachen im Strafprozeß” en: ESSER, Albin; GOYDKE, Jürgen; RÜDIGER, Kurt. (Eds), Strafverfahrensrecht in Theorie und Praxis. Festschrift für Lutz, Meyer-Gossner. München: C.H. Beck, 2001, p. 61.

${ }^{29}$ Naucke considera equivocado tratar separadamente distintas áreas jurídico-penales y plantea algunas líneas generales para la construcción de ese Derecho penal global. NAUCKE, Die Wechselwirkung, cit. nota $\mathrm{n}^{\circ} 15$, p. 166.
} 
HERRERA, Mercedes. "La negociación en el proceso penal desde la dogmática del Derecho penal. Especial referencia a los ordenamientos español y peruano".

sistema jurídico penal global ${ }^{30}$. Sin embargo, se está aún en los comienzos del intento de sistematizar la ciencia global del Derecho penal, a tal punto que la doctrina no se atreve a hacer afirmaciones que gocen de consenso ${ }^{31}$.

Winfried Hassemer sostiene que a los costos de un Derecho penal moderno pertenece también la corrupción del proceso penal y menciona como ejemplo la negociación en el mismo. Señala también, que este fenómeno tiene sus raíces en el Derecho material y se presenta como un medio para superar la modernización del Derecho penal ${ }^{32}$. Y añade: "Todos estos instrumentos de forma conjunta contravienen la tradición liberal del Derecho penal. Ellos -desde mi perspectiva- no son, en sentido estricto, una nueva opción, sino más bien, un resignado retroceso ante las necesidades del Derecho penal moderno" 33 .

Estoy de acuerdo en parte con lo expuesto por este autor, puesto que la negociación en el proceso penal es un fenómeno que tiene parcialmente sus raíces en la expansión del Derecho penal, que ha dado lugar a una sobrecarga procesal. Ante la abundancia de causas por resolver, la negociación en el proceso penal se presenta como una de las alternativas "estrella" para combatir el exceso de carga en las fiscalías y tribunales ${ }^{34}$. En este sentido, la negociación en el proceso penal es una salida de emergencia ante la ampliación del ámbito de intervención del Derecho penal. Sin embargo, el principal problema no radica en el origen de este fenómeno, sino en cómo se ha extendido.

\section{La prevención general como fin de la pena.}

La pena como institución jurídico-penal suscita básicamente dos preguntas: a) la cuestión de la justificación general de la institución de la pena; y b) la pregunta sobre la justificación de la pena concreta que se impone al autor (la medida de la pena) ${ }^{35}$. Sin embargo, a pesar de muchos siglos de discusión, todavía no está claro en qué relación lógica se encuentra la necesidad social de la pena y la justificación de la misma frente al autor ${ }^{36}$.

La primera pregunta atañe al fin de la pena, a la justificación de la injerencia estatal a través de la pena frente a la comunidad. Su discusión se introdujo en Alemania con la teoría

\footnotetext{
${ }^{30}$ Cfr. Prólogo de WOLTER Jürgen; FREUND, Georg (Eds.), Straftat, Strafzumessung und Strafproze $\beta$ im gesamten Strafrechtssystem. Straftatbegriff, Straftatzurechnung, Strafrechtszweck, Strafausschluß, Strafverzicht, Strafklagverzicht. Heildeberg: Müller, 1996.

${ }^{31}$ ROXIN, Claus, Strafrecht Algemeiner Teil. 4ª ed., Múnich: Verlag C.H, 2006, p. 198.

${ }^{32}$ HASSEMER, Winfried, "Kennzeichen und Krisen des modernen Strafrechts", ZRP N 10 (1992), pp. 382383.

${ }^{33}$ HASSEMER, “Kennzeichen”, cit. nota n 33, p. 383.

${ }^{34}$ En este sentido SILVA SÁNCHEZ, Jesús-María, La expansión del Derecho penal. Aspectos de la Política Criminal en las sociedades post-industriales. Montevideo-Buenos Aires: Editorial B de f, 2011, p. 78.

35 VON HIRSCH, Andrew; JAREBORG, Nils, Strafmaß und Strafgerechtigkeit. Die deutsche Strafzumessungslehre und das Prinzip der Tatproportionalität. Forum, Bonn: Godesberg, 1991, p. 11.

36 SCHÜNEMANN, Bernd, "Zum Stellenwert der positiven Generalprävention in einer dualistischen Straftheorie", en: SCHÜNEMANN, Bernd; VON HIRSCH, Andrew; JAREBORG, Nils (Eds.), Positive Generalprävention. Kritische Analysen im deutsch-englischen Dialog. Uppsala-Symposium 1996, C.F. Heildeberg: Müller, 1998, p. 113.
} 
Polít. crim. Vol. 11, No 21 (Julio 2016), Art. 9, pp. 229-263.

[http://www.politicacriminal.cl/Vol_11/n_21/Vol11N21A9.pdf]

retributiva desarrollada por Kant y Hegel y sigue siendo objeto de intenso debate en la doctrina penal $^{37}$.

Actualmente, la mayor parte de la doctrina penal postula -con diversos matices- que el fin de la pena reside en la prevención general de delitos ${ }^{38}$.

Anselm Feuerbach, a quien se considera como el fundador de la ciencia jurídico-penal moderna $^{39}$, fue el primero que desarrolló una teoría de la prevención general. Según este autor, para que la pena pueda prevenir lesiones de derechos es necesario que exista una coacción psicológica. La amenaza penal (amenaza de un mal a través de la que actúa la coacción psicológica) exige, como condición de eficacia, la imposición y ejecución de la pena; es decir, que el mal sea efectivamente impuesto ${ }^{40}$. En ese sentido, la teoría de la prevención general de Feuerbach es, en primer lugar, una teoría de la amenaza penal, pero también una teoría de la imposición y ejecución de la pena, porque hace depender la eficacia de la amenaza de la imposición efectiva de la pena ${ }^{41}$.

La teoría de la prevención general positiva ${ }^{42}$ fue formulada por primera vez con más fuerza por Jakobs ${ }^{43}$. Este autor entiende la pena como una reacción normativa frente a la ruptura de la norma, así se demuestra que la norma debe seguir vigente. Esta reacción se produce con menoscado de ciertos bienes del responsable de la ruptura de la noma (auf kosten des

${ }^{37}$ ROXIN, Claus, "Wandlungen der Strafzwecklehre", en: Grunfragen staatlichen Strafens. FS für Heinz Müller-Dietz zum 70. Geburstag. Múnich: C.H. Beck, 2011, p. 701.

38 NOLL, Peter, "Schuld und Prävention; Rationalisierung des Strafrechts" en: GEERDS, Friedrich; NAUCKE, Wolfgang (Eds.), FS für Hellmuth Mayer zum 70. Geburstag am 1. Mai 1965. Berlin: Duncker \& Humblot, 1966, p. 227; WOLFF, Ernst Amadeus, "Das neuere Verständnis von Generalprävention", ZStW 97 (1985), Berlin: De Gruyter, p. 792; MÜLLER-TUCKFELD, Jens Christan, Integrationsprävention. Studien zu einer Theorie der gesellschaftlichen Funktion des Strafrechts. Peter Lang, 1997; HÖRNLE, Tatjana; VON HIRSCH, Andrew, "Positive Generalprävention und Tadel" en: VON HIRSCH/JAREBORG, Positive Generalprävention, cit. nota $\mathrm{n}^{\circ} 36$, pp. 85 y ss.; ROXIN, Strafrecht, cit. nota n ${ }^{\circ} 31$, p. 85.

${ }^{39}$ ROXIN, Strafrecht,cit. nota ${ }^{\circ} 31$, p. 78.

${ }^{40}$ FEUERBACH, Anselm, Lehrbuch des gemeinen in Deutschland gültigen Peinlichen Rechts. Editado por Mittermaier, $14^{\circ}$ ed., aumentada, Giessen: Editorial Georg Friedrich, 1847, p. 38.

${ }^{41}$ ROXIN, Strafrecht, cit. nota ${ }^{\circ} 31$, p. 79.

${ }^{42}$ Dentro de esta teoría, la prevención general positiva ha gozado durante décadas de preeminencia en la ciencia jurídico penal alemana en lo que atañe a la existencia y configuración del Derecho VON HIRSCH/ JAREBORG, Strafmaß und Strafgerechtigkeit, cit. nota ${ }^{\circ} 35$, p. 9 . No obstante, en los últimos años, cada vez más autores se inclinan por una teoría dualista que integra (en distinto grado) la prevención general positiva y negativa. Incluso el propio Roxin afirma que hoy en día no se pueden separar nítidamente ambas formas de prevención general. ROXIN, Strafrecht, cit. nota ${ }^{\circ} 31$. Asimismo, un sector de la doctrina pone énfasis en la complementariedad de la teoría absoluta y relativa de la pena. Por ejemplo, Streng señala que tanto la teoría absoluta como la teoría relativa de la pena son irrenunciables y la pena justa debe, por tanto, considerarse, bajo el aspecto de la generalidad como del autor. STRENG, Franz. "Die absolute Theorie als wahrer Kern der relativen Straftheorie?", en: HILGENDORF, Eric; RENGIER, Rudolf (Eds.), FS für Wolfgang Heinz. Zum 70. Geburtstag. Baden-Baden: Nomos, 2012, p. 679. Jescheck y Weigend manifiestan que retribución y prevención no son objetos irreconciliables, puesto que la pena se impone para proteger a la sociedad frente a futuros delitos, constituye también una compensación de la culpa del autor. JESCHECK, Hans-Heinrich; WEIGEND, Thomas, Lehrbuch des Strafrechts. Allgemeiner Teil. Berlin: Duncker \& Humblot, 1996, p. 69.

${ }^{43}$ Un esquema en JAKOBS, Günther, Schuld und Prävention. Mohr: Tübingen, 1976 y fue desarrollada en Strafrecht Allgemeiner Teil. Die Grundlagen und die Zurechnungslehre. Berlin: De Gruyter, 1983, pp. 4 y ss. 
HERRERA, Mercedes. "La negociación en el proceso penal desde la dogmática del Derecho penal. Especial referencia a los ordenamientos español y peruano".

Täters $)^{44}$. La demostración de la vigencia de la norma a expensas del autor, supone un mal, pero con ello la pena no ha cumplido todavía su función, ésta se realiza con la estabilización de la norma lesionada ${ }^{45}$.

Para Jakobs, la pena cumple una función preventiva en la medida que protege las interacciones sociales, el modelo de orientación que se ve cuestionado con el delito ${ }^{46}$. Los destinatarios de la pena (de la acción comunicativa de la pena) son todos los hombres, quienes no podrían vivir sin interacciones sociales. Así, la acción comunicativa de la pena les proporciona un modelo de orientación. La contradicción frente a la ruptura de la norma a través de la pena tiene como finalidad proteger el modelo de orientación, y por tanto, una tarea preventiva. Con la pena se confirma la vigencia de la norma frente a la generalidad ${ }^{47}$.

Posteriormente, Jakobs ha introducido una modificación en su teoría de la prevención general positiva al incluir la imposición de un dolor penal: "El dolor sirve al aseguramiento cognitivo de la vigencia de la norma; este es el fin de la pena, así como su significado es la contradicción contra la negación de la vigencia de la norma por el delinquente" ${ }^{\text {. }}$. Con ello, Jakobs ha reconocido que la prevención general negativa (o prevención de intimidación) se encuentra dentro de la positiva, en tanto considera necesario que la pena produzca miedo en los autores potenciales. Postula además, que sólo a través del miedo la pena puede cumplir su rol de orientación tanto del autor como de la víctima potencial que espera se produzca el efecto de abstención a través del miedo, así se garantiza la vigencia de la norma. Si esto no ocurriese, se produciría una decepción y se dejaría de confiar en la vigencia de la norma ${ }^{49}$. Para este autor, la prevención general negativa no actúa directamente, porque el fin perseguido no es el miedo sino la fidelidad a la norma ${ }^{50}$.

${ }^{44}$ JAKOBS, Günther. Strafrecht Allgemeiner Teil. Die Grundlagen und die Zurechnungslehre, 2da ed. revisada y ampliada, Berlin: De Gruyter, 1993, p. 5.

${ }^{45}$ JAKOBS, Strafrecht Allgemeiner, cit. nota ${ }^{\circ} 44$, p. 6.

${ }^{46}$ JAKOBS, Strafrecht Allgemeiner, cit. nota ${ }^{\circ} 44$, p. 13.

${ }^{47}$ JAKOBS, Strafrecht Allgemeiner, cit. nota ${ }^{\circ}$ 44, pp. 13 y ss.

${ }^{48}$ JAKOBS, Günther, Staatliche Strafe. Bedeutung und Zweck. Paderborn: Ferdinand Schöningh, 2004, p. 29."Der Schmerz dient der kognitiven Sicherung der Normgeltung; das ist der Zweck der Strafe, so wie der Widerspruch gegen die Geltungsverneinung durch den Verbrecher ihre Bedeutung ist".

${ }^{49}$ JAKOBS, Staatliche Strafe, cit. nota $\mathrm{n}^{\circ} 48$, pp. 32 y ss.

${ }^{50}$ JAKOBS, Staatliche Strafe, cit. nota $n^{\circ} 48$. Uno de los problemas que suscita la teoría de la prevención general positiva de Jakobs es que no hace referencia al ámbito de protección de la norma, a los criterios objetivos que legitiman la protección de ésta. GÜNTHER, Klaus, "Die Person der personalen Rechtsgutslehre“, en: NEUMANN, Ulfrid; PRITTWITZ, Cornelius (Eds.), Personale Rechtsgutslehre und „Oferorientierung im Strafrecht“. Frankfurt am Maim: Peter Lang, 2007, p. 89: Detrás de la norma subyacen los valores que el ordenamiento jurídico protege. No se trata de proteger la norma en sí misma, o asegurar su vigencia a través de la imposición de la pena; sino de proteger a los bienes jurídicos de forma subsidiaria. SCHEINFELD, Jörg, "Normschutz als Strafrechtsgut? Normentheoretische Überlegungen zum legitimen Strafen“, en: HEINRICH, Manfred; JÄGER, Christian; SCHÜNEMANN, Bernd; et. al. (Eds.), Strafrecht als Scientia Universalis. FS für Claus Roxin zum 80. Geburtstag am 15. Mai 2011.Vol. I, Berlin: De Gruyter, 2011, pp. 183 y ss. En esta línea, Silva Sánchez manifiesta que la falta de estudio profundo de los elementos que configuran la identidad normativa de la sociedad, especialmente de aquello que es nuclear en la misma, es un importante déficit que presenta la teoría de Jakobs. SILVA SÁNCHEZ, La expansión del Derecho penal, cit. nota $\mathrm{n}^{\circ} 34$, p. 128. 
Polít. crim. Vol. 11, No 21 (Julio 2016), Art. 9, pp. 229-263.

[http://www.politicacriminal.cl/Vol_11/n_21/Vol11N21A9.pdf]

Como punto de partida de su teoría de la pena Roxin afirma que el fin de la pena sólo puede ser preventivo; ya que las normas penales sólo se justifican cuando se ordenan a la protección de la libertad del individuo y a las condiciones del orden social que salvaguardan ésta. De este fin resulta también, que la prevención general y la especial deben estar una junto a la otra, puesto que la pena influye tanto en la generalidad como en el individuo ${ }^{51}$.

Según este autor, el fin de la amenaza penal es primero sólo general-preventivo. Más adelante, al imponer la pena, se toman en cuenta necesidades tanto generales como especial-preventivas y en la ejecución la prevención especial estará en primer plano. Estos fines nunca actúan separados, sino que tienen distinto peso (importancia), es decir su ponderación es distinta según la etapa de la que se trate ${ }^{52}$.

Es posible distinguir la prevención general como política criminal y atribuirle un significado mucho más amplio que la prevención general como teoría de la pena. Como parte de la política criminal, la prevención de delitos es perseguida por el Estado a través de mecanismos jurídico-penales y extra jurídico-penales; pero también la sociedad y la familia pueden contribuir activamente a la prevención de delitos. En cambio, al tratar de la prevención general como fin de la pena, se hace referencia a lo que se puede alcanzar a través de la misma ${ }^{53}$. Además, se debe considerar que la prevención general no sólo es una teoría de la pena, sino también una teoría del Derecho penal, que explica la función del Derecho penal y de las sanciones vinculadas a él. En este sentido, el fin más alto del Derecho penal es "proteger la sociedad de los daños sociales y custodiar los valores esenciales de la vida en común"

Actualmente, se distingue un aspecto positivo y uno negativo en la prevención general. El aspecto negativo tiene su origen en el concepto de intimidación. Se trata del punto de vista desarrollado por Feuerbach ${ }^{55}$. Sin embargo, hoy en día la prevención general negativa es entendida por varios autores en un sentido más amplio.

El aspecto positivo de la prevención general se define como el mantenimiento de la confianza de la población en la existencia y fuerza de ejecución del ordenamiento. La pena tiene entonces la tarea de "demostrar la inviolabilidad del ordenamiento jurídico frente a la comunidad jurídica y de esa manera fortalece la fidelidad al Derecho en la población"56. La pena actúa de forma preventiva en cuanto presenta a los potenciales infractores que comportamientos deben evitar o realizar, y en cuanto a la imposición y medición de la

\footnotetext{
${ }^{51}$ ROXIN, Strafrecht, cit. nota ${ }^{\circ} 31$, p. 85.

${ }^{52}$ ROXIN, Strafrecht, cit. nota ${ }^{\circ} 31$, p. 87.

${ }^{53}$ LUZÓN PEÑA, Diego-Manuel, „Generalprävention, Gesellschaft und Psychoanalyse“, en: GA, Heidelberg: Decker's, 1984, pp. 396 y ss.

${ }^{54}$ Cfr. SCHÖCH, Heinz, „Empirische Grundlagen der Generalprävention” en: VOGLER, Theo (Ed.), FS für Hans-Heinrich Jescheck zum 70. Geburtstag. Berlín: Duncker \& Humblot, 1985, pp. 1083 y ss.

${ }^{55}$ ROXIN, Strafrecht, cit. nota ${ }^{\circ} 31$, p. 80.

${ }^{56}$ Cfr. ROXIN, Strafrecht, cit. nota $\mathrm{n}^{\circ} 31$.
} 
HERRERA, Mercedes. "La negociación en el proceso penal desde la dogmática del Derecho penal. Especial referencia a los ordenamientos español y peruano".

pena, éstos se presentan como aspectos preventivo-generales, porque a través de ellos, la confianza de los ciudadanos en la inviolabilidad del ordenamiento jurídico se documenta ${ }^{57}$.

La prevención general positiva presenta en realidad dos aspectos: el primero reside precisamente en la idea de preservación del orden jurídico. En este sentido, el Estado debe imponer penas para mantener la seguridad y preservar así el orden. De tal forma, que la justificación de la pena está en esta función de salvaguarda de un orden que debe ser reconocido y respetado (de no ser así se disolvería) ${ }^{58}$. Considero que, aquí se agota el significado de la prevención general positiva y que la confianza en la inviolabilidad del ordenamiento se documenta a través de factores externos: la aplicación de la pena a los culpables de acuerdo con el contenido de la amenaza penal da razón tanto de la seriedad de la norma, como de que la efectiva aplicación del Derecho penal cumple la función de proteger bienes jurídicos a través de la imposición de la pena.

El otro aspecto, muy distinto, es la prevención general como la influencia en el modo de pensar de los ciudadanos y con ello impedir que cometan otros delitos ${ }^{59}$.

Una pretendida influencia o injerencia en la esfera interna de los ciudadanos es ajena al ámbito de intervención legítimo del Estado; toda vez que los motivos por los que alguien se abstiene de cometer un delito, quedan fuera del ámbito penal. La moralidad del ciudadano no le concierne en absoluto al Estado ${ }^{60}$; por ello, el Estado no está legitimado para utilizar argumentos relacionados con la moral (también en un sentido amplio) para limitar la libertad del ciudadano. Así, el límite que ignora la prevención general que se formula en términos de ingerencia interna sobre la conciencia o las disposiciones interiores del ciudadano, es que éste es libre para decidir entre lo bueno y lo malo ${ }^{61}$ y el Estado no tiene Derecho debido a criterios filosóficos o religiosos a intervenir en la esfera de libertad del mismo ${ }^{62}$.

La confianza en la vigencia o inviolabilidad del ordenamiento se materializa a través de aspectos externos: la aplicación de la pena de acuerdo con la amenaza penal y demás criterios jurídico-penales y procesales. Esto muestra la seriedad de la norma y en ese sentido se puede hablar de confianza de la población en la fuerza de la norma penal.

La prevención general es, en efecto, un complejo entramado, que sólo es susceptible de comprobación empírica de un modo limitado. Conceptos como "seria afectación de la

\footnotetext{
${ }^{57}$ GROPP, Walter, Strafrecht Allgemeiner Teil. 3a ed., Heildeberg: Springer, 2005, p. 38.

58 ZIPF, Heinz, "Die verteidigung der Rechtsordnung” en: FURSCH, Wolfgang; SCHMID, Werner (Eds.), .FS für Hans-Jürgen Bruns zum 70. Geburstag. Lahn: Carl Heyman, 1978, p. 212.

${ }^{59}$ ZIPF, "Die verteidigung", cit. nota ${ }^{\circ} 58$, p. 212.

${ }^{60}$ FEIJOO SÁNCHEZ, Bernardo, "Positive Generalprävention, en: PAWLIK, Michael; ZACZYK, Rainer (Eds.), FS für Günther Jakobs.Zum 70 Geburstag am 26 Juli 2007, Berlin: Carl Heymans, 2007, p. 86.

61 GRECO, Luis, Lebendiges und Totes in Feuerbachs Straftheorie. Ein Beitrag zur Gegenwärtigen strafrechtlichen Grundlagendiskussion. Berlin: Duncker \& Humblot, 2009, p. 400; KORIATH, Heinz, "Zum Streit um die positive Generalprävention-Eine Skizze” en: RADTKE, Henning; MÜLLER, Egon, et.al. (Eds.), Muss Strafe sein?, Baden-Baden: Nomos, pp. 58 y ss.

${ }^{62}$ ROXIN, Strafrecht, cit. nota ${ }^{\circ} 31$, p. 91.
} 
Polít. crim. Vol. 11, No 21 (Julio 2016), Art. 9, pp. 229-263.

[http://www.politicacriminal.cl/Vol_11/n_21/Vol11N21A9.pdf]

confianza en el Derecho por parte de la población" o "conmoción de la confianza de la población en la inviolabilidad del ordenamiento y protección del orden social" empíricamente pueden proporcionar información sobre la actitud y los conocimientos del ciudadano. Sin embargo, la ponderación de estos resultados empíricos y su valoración de acuerdo con las exigencias del Deber ser jurídico-penal sigue siendo una cuestión normativa $^{63}$.

La discusión acerca de la dificultad de probar empíricamente la verdadera eficacia preventiva de las normas penales no es un tema zanjado. De una parte, a través de una mera observación se constata, que a pesar de toda la criminalidad, la mayoría de la población se comporta de modo fiel al Derecho. Con ello, sin embargo, no se resuelve aún la pregunta de en qué medida esa fidelidad al Derecho se puede adjudicar a la prevención general positiva o negativa ${ }^{64}$.

De otra parte, los estudios empíricos realizados muestran que la eficacia preventiva del Derecho penal es limitada, mucho más modesta de lo que muchos autores suponen ${ }^{65}$. La prevención general como tal es una tarea que no le corresponde exclusivamente al Derecho penal, sino que se refiere a la generalidad de los ciudadanos ${ }^{66}$. Como afirma Hassemer hay muchos otros medios estatales o sociales que pueden contribuir quizás en mayor medida que las penas a la prevención de delitos ${ }^{67}$.

De acuerdo con lo antes expuesto, la prevención general no es una teoría empírica, sino una teoría normativa y, en ese sentido, sólo son susceptibles de comprobación empírica algunos de sus componentes. No obstante, no se puede negar la eficacia preventiva de las normas penales; ya que aunque su eficacia pueda ser menor a la que le atribuye la doctrina jurídicopenal, es necesaria para mantener el orden social y la paz jurídica. Sobre este punto, se puede concluir con Roxin, que aunque la prevención general se base en presunciones psicológicas, apenas se puede contradecir en la práctica; puesto que a pesar de la criminalidad existente la mayoría de la población se mantiene fiel al Derecho ${ }^{68}$.

Ahora bien, la eficacia preventiva de la amenaza penal depende de la existencia y funcionamiento de un sistema de persecución y sanción efectiva, para que se confirme la seriedad de la amenaza penal (o anuncio de sanciones) ${ }^{69}$. En qué medida se produce el efecto preventivo general es una cuestión difícil de determinar empíricamente. Sin

\footnotetext{
${ }^{63} \mathrm{SCHÖCH}$, "Empirische Grundlagen”, cit. nota $\mathrm{n}^{\circ} 54$.

${ }^{64}$ ROXIN, Strafrecht, cit. nota $\mathrm{n}^{\circ} 31$.

65 A esta conclusión llega también HÖRNLE, Tatjana, „Claus Roxins Straftheoretischer Ansatz“ en: HEINRICH, Manfred; JÄGER, Christian; ACHENBACH, Hans; AMELUNG, Knut; BOTTKE, Wilfried; HAFFKE, Bernhard; SCHÜNEMANN, Bernd; WOLTER, Jürgen (Eds.), Strafrecht als Scientia Universalis. FS für Claus Roxin zum 80. Geburtstag am 15. Mai 2011. Berlin: De Gruyter, 2011, p. 8.

${ }^{66}$ KAUFMANN, Armin, Die Aufgabe des Strafrechts. Düsseldorf: Westdeutscher Verlag, 1983, p. 17.

${ }^{67}$ HASSEMER, Einführung in die Grundlagen des Strafrechts, cit. nota ${ }^{\circ} 17$, pp. 310 y ss.

${ }^{68}$ ROXIN, Strafrecht, cit. nota ${ }^{\circ} 31$, p. 81.

${ }^{69}$ De acuerdo con estudios empíricos hay una relación entre la intensidad de la persecución penal y la tasa de criminalidad. DÖLLING, Dieter, „Generalprävention durch Strafrecht: Realität oder Illusion?“, Zeitschrift für die gesamte Strafrechtswissenschaft, vol. 102 (1990), pp. 3 y ss.; GRECO, Lebendiges, cit. nota n 61, p. 386.
} 
HERRERA, Mercedes. "La negociación en el proceso penal desde la dogmática del Derecho penal. Especial referencia a los ordenamientos español y peruano”.

embargo, no se puede negar que cada delito cometido contradice la prevención general del Derecho penal; sin duda se cometerían más delitos si no hubiera justicia penal ${ }^{70}$.

Que la pena tiene un fin tanto negativo como positivo es un punto de vista aceptado por diversos autores $^{71}$ en los últimos años, según se vio supra. A continuación, se desarrollará brevemente el punto de vista particular que aquí se asume, así como las posturas doctrinales que se toman como referente próximos.

Schünemann considera que la amenaza penal agregada a la prohibición contenida en la norma primaria tiene eficacia preventiva tanto positiva como negativa; puesto que ya la prohibición prevista con la amenaza fortalece la conciencia jurídica general y comunica el valor del bien jurídico (esto sería prevención general positiva), mientras que la pena con la que se amenaza anticipa el efecto de intimidación, es decir, produce prevención general negativa.

Concluye que la importancia y el significado de la prevención general positiva se ha sobrevalorado. Propone, en cambio, que el centro de la teoría de la pena esté en la prevención general de amenaza, que presenta tanto un aspecto positivo, integrativo, como un aspecto negativo ${ }^{72}$.

$\mathrm{Su}$ teoría de la prevención general de amenaza, como fin de la pena, (Androhungsgeneralprävention) presupone el reproche culpable al autor por el acto lesivo. La culpa legitima la pena, porque el autor no ha evitado el acto para él evitable y, de acuerdo con la lógica de la prevención general de amenaza, el autor que ha hecho caso omiso de ella debe ser sancionado, para que la amenaza no resulte después un vacío, en los términos de la clásica teoría de Feuerbach ${ }^{73}$. Al mismo tiempo, afirma que la teoría de la pena debe desarrollarse desde la amenaza penal, de tal suerte que en la imposición de la sanción también tenga la preferencia la norma de comportamiento y la sanción vinculada a ella. En la ejecución de la sanción se pueden considerar adicionalmente otros puntos de vista, como por ejemplo, aspectos especial-preventivos, que están exclusivamente orientados al futuro $\mathrm{y}$, por ello, no pueden ser considerados en la norma de comportamiento $^{74}$.

\footnotetext{
${ }^{70}$ JESCHECK/WEIGEND, Lehrbuch des Strafrechts, cit. nota ${ }^{\circ}$ 42, p. 69.

${ }^{71}$ Además de Jakobs y Roxin, quienes aceptan la estrecha relación ambos tipos de prevención general. Están a favor de integrar ambas vertientes: HÖRNLE, Tatjana, Straftheorien. Tübingen: Mohr Siebeck, 2011, p. 28; KUHLEN, Lothar, "Anmerkungen zur positive Generalprävention", en: SCHÜNEMANN/VON HIRSCH/JAREBORG, Positive Generalprävention, cit. nota $\mathrm{n}^{\circ} 36$, pp. 62 y ss.; MIR PUIG, Santiago, Función de la pena y teoría del delito en el Estado social y democrático de Derecho. 2a ed., Barcelona: Bosch, 1982, p. 31.

${ }^{72}$ SCHÜNEMANN, "Zum Stellenwert”, cit. nota n 36, pp. 120 y ss.

${ }^{73}$ SCHÜNEMANN, "Zum Stellenwert”, cit. nota n 36, p. 117.

${ }^{74}$ SCHÜNEMANN, "Zum Stellenwert”, cit. nota nº 36.
} 
Polít. crim. Vol. 11, No 21 (Julio 2016), Art. 9, pp. 229-263.

[http://www.politicacriminal.cl/Vol_11/n_21/Vol11N21A9.pdf]

Una postura parecida mantiene Luzón Peña ${ }^{75}$. Para este autor, la prevención general tiene un aspecto negativo o de intimidación y un aspecto positivo. Sin embargo, considera que este último aspecto es secundario y que se deduce de la prevención general de intimidación (aspecto primario) como consecuencia de su eficacia y que ambos aspectos deben ser correlativos. En ese sentido, postula que la prevención general positiva no es una categoría autónoma $^{76}$. Sobre este último aspecto, Schünemann sostiene también que la prevención general positiva es un efecto que acompaña al sistema, pero que por si mismo no tiene un significado sistemático como fin de la pena ${ }^{77}$.

Comparto parcialmente el punto de vista de Schünemann y Luzón Peña, en cuanto considero de recibo que la prevención general negativa debe estar en el centro de la teoría de la pena. Sin embargo, disiento en lo que atañe al papel que atribuyen a la prevención general positiva, como se expondrá más adelante.

Aquí se postula que, con la amenaza penal (prevención general negativa) -que como afirmaba Feuerbach ${ }^{78}$ no puede limitarse a la amenaza, sino que su eficacia depende de la imposición y ejecución de la pena- el fin que se busca es la prevención general positiva. En este sentido, el fin intermedio o mediato de la pena es la prevención general negativa.

La prevención general negativa no significa dirigirse a hombres que actúan de modo automático frente a un impulso (por ejemplo, el miedo), sino a hombres que pueden tanto entender las reglas de prudencia (Klugheitsregeln) como decidirse libremente a actuar conforme a ellas. Tal como concluye Greco, después de analizar la teoría de la pena de Feuerbach, la intimidación no debe entenderse en sentido psicológico, referida a motivos como el miedo. Intimidación significa más bien el anuncio (Bekanntmachung) de reglas inteligentes o reglas de prudencia, razones de actuación para no cometer delitos y no de reglas relacionadas con la moral. Una intimidación tal puede ser defendida como fin de la amenaza penal cuando se parte de premisas empíricas basadas en el discurso de lo cotidiano, de que los hombres se dejan motivar por razones ${ }^{79}$.

Hörnle propone hablar de prevención general de anuncio (“Ankündingungsgeneralprävention") en lugar de prevención general de amenaza, puesto que el término "amenaza" es susceptible de críticas, sobre todo la de tratar a la persona humana como un ser irracional. Hoy en día -afirma esta autora- es mejor hablar de

${ }^{75}$ LUZÓN PEÑA, Diego-Manuel, Medición de la pena y sustitutivos penales. Madrid: Publicaciones del Instituto de Criminología de la Universidad Complutense de Madrid, 1979, pp. 27 y ss. LUZÓN PEÑA,"Generalprävention“, cit. nota n 53, pp. 396 y ss.

${ }^{76}$ LUZÓN PEÑA, "Generalprävention", cit. nota n ${ }^{\circ} 53$, pp. 395 y ss.

${ }^{77}$ SCHÜNEMANN, "Zum Stellenwert", cit. nota n 36, p. 119.

${ }^{78}$ FEUERBACH, Lehrbuch des gemeinen, cit. nota $\mathrm{n}^{\circ} 40$, p. 39.

${ }^{79}$ GRECO, Lebendiges, cit. nota n 61, p. 419. También: HÖRNLE, “Claus Roxins”, cit. nota n 65, p. 13. También Schünemann, señala que la norma de prohibición actúa sobre el proceso de motivación de los ciudadanos y presupone la libertad de actuación, el haber podido evitar la lesión del bien jurídico. SCHÜNEMANN, "Zum Stellenwert", cit. nota ${ }^{\circ} 36$, pp. 118 y ss. En esta línea, Noll afirma que la prevención normativa no actúa en primer lugar por la intimidación, a través de la amenaza de la pena, sino a través de la orientación (la norma misma) y la apelación a la inteligencia y a la capacidad de autodeterminación. NOLL, "Schuld und Prävention", cit. nota n 38, p. 227. 
HERRERA, Mercedes. "La negociación en el proceso penal desde la dogmática del Derecho penal. Especial referencia a los ordenamientos español y peruano".

anuncios de sanciones, ya que el hombre es capaz de entender el sentido de las normas de prohibición y decidirse libremente a actuar ${ }^{80}$. Tales anuncios funcionan como estímulos, que tienen un rol en contextos complejos de actuación ${ }^{81}$.

Cuando se renuncia a una intimidación negativa de tipo psicológico y se suscribe un concepto como el antes esbozado, es -desde mi perspectiva- irrelevante la denominación de prevención general negativa o anuncio de sanciones. En ambos casos se presupone la libertad de actuación y la apelación a razones de prudencia.

Contra la crítica según la cual, el aspecto negativo de la prevención general o intimidación según el modelo de Feuerbach no tendría aplicación para la mayoría de los casos, puesto que hoy en día son muy pocos los autores que cometen un delito con tanta premeditación que resulten afectados por la intimidación ${ }^{82}$, se puede aducir que esta objeción se aplica válidamente a una prevención general negativa de tipo psicológico, pero no cuando se entiende la prevención general negativa como el anuncio de sanciones que apela al carácter libre de los destinatarios de la norma.

Con el anuncio de sanciones o prevención general negativa (fin intermedio) y con la imposición de la pena se persigue proteger la libertad del individuo y las condiciones del orden social que salvaguardan ésta. Por ello, el fin "último" de la pena sólo puede estar en la prevención general positiva ${ }^{83}$.

\footnotetext{
${ }^{80}$ HÖRNLE, Straftheorien, cit. nota $\mathrm{n}^{\circ} 71$, pp. 8 y ss.

${ }^{81}$ HÖRNLE, Straftheorien, cit. nota $\mathrm{n}^{\circ} 71$, pp. 12 y ss.

${ }^{82}$ ROXIN, Strafrecht, cit. nota $n^{\circ} 31$, p. 80.
}

${ }^{83}$ En esta línea, Hassemer considera que el fin preventivo del Derecho penal no es la intimidación, sino la afirmación y protección de las normas fundamentales. Entiende que el Estado se sirve de la amenaza y la ejecución de la pena para alcanzar la prevención general cuando otros medios extra jurídico-penales han fracasado Asimismo, manifiesta que junto al derecho penal hay otros medios menos violentos dirigidos también al fin de la prevención de delitos. este cuando otros medios de control han fracasado o no son competentes para intervenir. HASSEMER, Einführung in die Grundlagen des Strafrechts, cit. nota n ${ }^{\circ} 26, \mathrm{pp}$. 295 y ss. También Roxin, afirma que la prevención general negativa está dentro de la positiva, y éstas no pueden separarse porque la confianza en la fuerza de aplicación del ordenamiento depende en parte de la eficacia intimidatoria del Derecho penal. ROXIN, Strafrecht, cit. nota $\mathrm{n}^{\circ} 31$, pp. 147 y ss. Incluso algunos autores que asumen la prevención general negativa en términos de intimidación, es decir, de acuerdo a la teoría de Feuerbach, atribuyen a ésta una función mediata, ya que ven detrás de la intimidación la estabilización de la norma, la protección del bien jurídico. Así, Wolff afirma que la prevención general negativa en su forma simple se orienta a la protección del bien jurídico. Para ello inflinge temor al ciudadano por medio de la amenaza de un mal. WOLFF, "Das neuere Verständnis", cit. nota n' 38 , p. 792. También Jescheck y Weigend son de la opinión, que la eficacia preventivo-general de la pena tiene un doble aspecto: por un lado, a través del miedo se intimida a cualquier persona de cometer un delito. Pero de otra parte, y como un aspecto más importante de la prevención general, que a través de la amenaza penal y el juzgamiento de los culpables se contribuye en gran medida a la prevención general positiva. JESCHECK/WEIGEND, Lehrbuch des Strafrechts, cit. nota n ${ }^{\circ} 42$, pp. 68 y ss.

Asimismo, Wohlers señala que el Derecho penal contribuye a que en el futuro la lesión de un bien jurídico no tenga lugar ya a través de la amenaza penal. Así, el efecto de intimidación estabiliza la vigencia de la norma.WOHLERS, Wolfgang, Deliktstypen des Präventionsstrafrechts. Zur Dogmatik modernen Gefährdungsdelikte. Berlin: Duncker \& Humblot, 2000, p. 215. En la misma línea, José de Sousa afirma que la intimidación a través de la amenaza penal debe contribuir al seguimiento de la norma.Cfr. SOUSA E 
Polít. crim. Vol. 11, No 21 (Julio 2016), Art. 9, pp. 229-263.

[http://www.politicacriminal.cl/Vol_11/n_21/Vol11N21A9.pdf]

A mi juicio, el anuncio de sanciones es susceptible de tener una eficacia intimidatoria. Sin embargo, no es necesario que ésta se produzca ${ }^{84}$. Para algunos destinatarios de la norma el anuncio de sanciones puede ser eficaz en virtud de otras razones, por ejemplo razones morales o religiosas ${ }^{85}$. Pero, esto es indiferente para el Estado, como se ha apuntado antes. El Estado no está legitimado y tampoco obligado a entrar en la esfera interna, es decir en los motivos últimos por los cuales una determinada persona deja de cometer un delito. Así, una persona puede abstenerse de matar a otra en virtud de motivos religiosos o morales, sin que haya pensado siquiera en las consecuencias jurídico-penales que podría causar la realización del delito.

\section{Efectos de la negociación en el proceso penal sobre la prevención general y sobre la función del Derecho penal.}

La eficacia de la construcción de un Derecho penal orientado a la prevención general depende también del proceso penal, pues es aquí donde tiene su campo de aplicación y porque, en definitiva, el Derecho procesal penal es parte del sistema global del Derecho penal (un subsistema) ${ }^{86}$.

El Derecho procesal penal prepara y organiza lo que el Derecho penal necesita para su eficacia; de tal suerte que, sin proceso penal no es posible la protección de bienes jurídicos ni la realización de los fines de la pena ${ }^{87}$. De modo indirecto, esta es también una "tarea" del Derecho procesal penal (la protección de bienes jurídicos), no de modo directo, pero si a través de la realización del Derecho penal.

Desde la perspectiva de la dogmática jurídico-penal sólo se puede renunciar a la pena si decae la competencia del autor respecto al hecho (por ejemplo porque no es culpable) o cuando éste se encuentra en una situación especial (por ejemplo, peligro de muerte) y por tanto, no es responsable penalmente por el hecho. También en estos casos es posible disminuir la pena si no concurren todas las circunstancias que ameritan la exclusión de responsabilidad penal ${ }^{88}$.

BRITO, José De, "Strafzwecke im Rechtsstaat" en: HERZOG, Felix; NEUMANN, Ulfrid (Eds.), FS für Winfried Hassemer zum 70. Geburstag am 17. Februar 2010. Heildeberg: C.F Müller, 2010, p. 308.

${ }^{84} \mathrm{No}$ obstante, en términos prácticos, la eficacia positiva de la pena se produce generalmente (y no necesariamente) a través de la negativa. Sobre este punto, considero que la siguiente reflexión de Roxin concierne al modo en cómo actúa la amenaza penal y no a nivel del fin de la pena. Este autor manifiesta que la prevención general positiva y negativa constituyen componentes de la misma categoría; ya que el ciudadano puede abstenerse de realizar el comportamiento descrito en la norma penal porque considera justa esa abstención, o porque reconoce esta prohibición como vinculante para él (nos encontraríamos entonces dentro del ámbito de la prevención general positiva) o por miedo a ser descubierto y sancionado. ROXIN, Claus, "Strafe und Strafzwecke in der Rechtsprechung des Bundesverfassungsgerichts" en: HASSEMER, Winfried; KEMPF, Ebehard; MOCCIA, Sergio (Eds.), In Dubio pro Libertate. FS für Klaus Volk zum 65. Geburtstag. Múnich: C.H. Beck, 2009, p. 611.

${ }^{85}$ A la misma conclusión llega GRECO en Lebendiges, cit. nota n ${ }^{\circ} 61$, p. 359.

${ }^{86}$ FREUND, Georg, "Der Zweckgedanke im Strafrecht", GA (1995), pp. 1-22.

${ }^{87}$ HASSEMER, Einführung in die Grundlagen des Strafrechts, cit. nota n ${ }^{\circ} 26$, p. 110.

${ }^{88}$ JAKOBS, Strafrecht Allgemeiner, cit. nota ${ }^{\circ}$ 44, p. 10. 
HERRERA, Mercedes. "La negociación en el proceso penal desde la dogmática del Derecho penal. Especial referencia a los ordenamientos español y peruano".

No existe una justificación jurídico-penal para admitir la negociación en el proceso penal. Pues ello supone modificar el modelo de orientación; es decir, el modo de proteger determinados bienes jurídicos (a los que el legislador, al tipificar una conducta como delictiva ha considerado merecedores de esa tutela concreta).

Con la negociación en el proceso penal se convierte a la norma de sanción en un objeto de negociación y con ello, se ve minado el carácter de imperativo categórico como fundamento del sistema de justicia penal ${ }^{89}$.

Cuando se permite la negociación en el proceso penal no se impone la pena que la protección del bien jurídico por razones preventivo-generales exige, sino una mucho menor y con ello, a largo plazo, se socava la tarea de protección de bienes jurídicos del Derecho penal $^{90}$.

Al dejar la determinación de las consecuencias jurídicas del delito en manos del poder de disposición de las partes (aunque con ciertas limitaciones), se afecta la eficacia preventiva del Derecho penal ${ }^{91}$. Esa disposición limitada, que los ordenamientos español y peruano conceden al acusado y al MP, se ubica fuera de la sistemática jurídico penal y de las consecuencias penales previstas inicialmente y constituye, por ello, un cierto régimen de excepción a la "regular" vigencia del Derecho penal. Así, la modificación de la pena por medio de la negociación en el proceso penal no está amparada por las categorías del delito, lo que produce importantes "agujeros en el sistema jurídico penal".

Sí, la prevención general exige que la prohibición se determine de modo concreto, para que pueda motivar al ciudadano a abstenerse de lesionar el bien jurídico en cuestión ${ }^{92}$, con la negociación en el proceso penal no se cumple esta exigencia, porque el objeto del mandato de prohibición está sujeto a la negociación entre la acusación y la defensa.

La prevención general, como efecto, se alcanza, en primer lugar con la creación de normas penales, que determinen con claridad el contenido del injusto del acto prohibido; también, con una medida de la pena que se oriente por la gravedad del hecho y la culpa del autor, que sea comprensible para los condenados y que se considere justa en la comunidad jurídica ${ }^{93}$. A este fin contribuye la norma misma, pero también la imposición y la ejecución de la pena, ya que de ello depende la eficacia preventiva de la norma ${ }^{94}$.

Una buena parte de la eficacia del Derecho penal reside precisamente en su significado comunicativo. Por ello cuando la certeza y la severidad del castigo se ponen en duda, se afecta con ello su eficacia preventiva ${ }^{95}$. La prevención general negativa está condicionada a

\footnotetext{
${ }^{89}$ SCHÜNEMANN, Bernd, „Strafrechtssystematisches Manifest““, GA (2006), p. 379.

${ }^{90}$ SCHÜNEMANN, ,Zur Kritik des amerikanischen“, cit nota ${ }^{\circ} 7$, p. 567.

${ }^{91}$ SCHÜNEMANN, Vom Tempel zum Marktplatz, cit. nota ${ }^{\circ} 27$.

${ }^{92}$ Sobre este punto ROXIN, Strafrecht, cit. nota $n^{\circ} 31$, p. 81.

${ }^{93}$ JESCHECK/WEIGEND, Lehrbuch des Strafrechts, cit. nota ${ }^{\circ}$ 42, p. 4.

${ }^{94}$ ROXIN, Strafrecht, cit. nota $n^{\circ} 31$, p. 79.

95 SILVA SÁNCHEZ, La expansión del Derecho penal, cit. nota ${ }^{\circ}$ 34, p. 80.
} 
Polít. crim. Vol. 11, No 21 (Julio 2016), Art. 9, pp. 229-263.

[http://www.politicacriminal.cl/Vol_11/n_21/Vol11N21A9.pdf]

la efectiva imposición de la pena prevista legalmente -según el modelo de Feuerbach-, de lo contrario el anuncio de sanciones se vacía de contenido. Pero también posee esta eficacia el miedo o aversión a las consecuencias sociales, laborales, personales que se derivan de la intervención del Estado para perseguir y sancionar el delito (por ejemplo el juicio oral o el mero procedimiento de investigación) ${ }^{96}$.

Como afirma Silva Sánchez, las reacciones privadas o desformalizadas en las que se renuncia a la igualdad, generalidad e imparcialidad, a fin de dar una respuesta más rápida al conflicto, privan al Derecho penal de su contenido simbólico, le quitan legitimidad a la reacción y disminuyen su eficacia preventiva ${ }^{97}$.

A través de la negociación en el proceso penal se ponen parcialmente a disposición del acusado y del Fiscal las consecuencias del delito. La eficacia del anuncio de sanciones (la prevención general negativa) se ve con ello disminuida, porque el autor sabe con antelación que a través de una negociación procesal puede recibir una considerable disminución de la pena que, en principio, le corresponde. Pero también se afecta la prevención general positiva, en la medida que disminuye la confianza de la población en la vigencia de la norma penal (que según el modelo asumido se materializa en factores externos y se consigue a través de la prevención general negativa). Tanto la comunidad como los potenciales autores ven que la norma jurídico-penal no es tomada en serio, lo que afecta también a la comunicación sobre el valor del bien jurídico.

Desde la óptica de la prevención general positiva, la pena debe contribuir al establecimiento de un marco jurídico penal que al mismo tiempo comunique el valor e importancia de ese bien jurídico, de su significado para el individuo, la comunidad y el ordenamiento jurídico $^{98}$. Sin embargo, con la negociación sobre la pena (a la que en el ordenamiento procesal penal peruano se le agrega además la disminución legal que se aplica de forma automática en cada terminación anticipada) se comunica un nuevo mensaje normativo a los destinatarios, y de este modo, se disminuye el grado de protección del bien jurídico previsto en la norma de conducta. La confianza en la vigencia de la norma o en la protección del bien jurídico afectado se debilita significativamente, y con ello la eficacia preventivo general negativa como fin intermedio y la prevención general positiva como fin "último" del Derecho penal.

Desde mi perspectiva, con la negociación en el proceso penal se corre el riesgo de la "disolución del Derecho penal"99. Aunque esta cuestión pueda parecer una utopía, la extensión de la negociación en el proceso penal, a pesar de que no llegaría a eliminar la

\footnotetext{
${ }^{96}$ LUZÓN PEÑA, Medición de la pena, cit. nota $n^{\circ} 75$, p. 52.

${ }^{97}$ SILVA SÁNCHEZ, La expansión del Derecho penal, cit. nota ${ }^{\circ} 34$, p. 82.

98 MÜLLER-DIETZ, Heinz. "Integrationsprävention und Strafrecht. Zum positiven Aspekt der Generalprävention” en: VOGLER, Theo; HERMANN, Joachim; KRÜMPELMANN, Justus et. al. (Eds.), Festschrift für Hans-Heinrich Jescheck. Berlin: Duncker \& Humblot, 1985, p. 822.

99 En esta línea, LÜDERSSEN, Klaus, "Verständigung im Strafverfahren. Das Modell uns seine Implikationen” en: MICHALKE, Regina; KIRSCH, Stefan (Eds.), Festschrift für Rainer Hamm sum 65. Geburstag am 24. Februar 2008. Berlin: De Gruyter Recht, pp. 419 y ss.
} 
HERRERA, Mercedes. "La negociación en el proceso penal desde la dogmática del Derecho penal. Especial referencia a los ordenamientos español y peruano".

intervención punitiva del Estado, si cambiaría el Derecho penal como sistema teórico, ya que afecta a su sistematicidad.

Hay una relación muy estrecha entre la protección de bienes jurídicos, como tarea del Derecho penal y la prevención general como fin de la pena, puesto que el uso del Ius Puniendi y, por ende, la pena estatal se legitima por el fin racional, es decir, a través de la tarea preventiva de protección de bienes jurídicos ${ }^{100}$. En interés de la comunidad jurídica en general, y a fin de garantizar una efectiva protección del bien jurídico, el Estado debe - de acuerdo con el principio de legalidad-perseguir y, de ser el caso, sancionar todo delito. Si ello no ocurriese, el monopolio en la persecución penal del Estado se vaciaría de contenido $^{101}$.

La función del Derecho penal supone la vigencia segura o irrompible de la norma. En consecuencia, la norma de prohibición (sus consecuencias jurídicas) no puede ser objeto de negociación entre las partes en el proceso penal. Así, la norma jurídico-penal constituye un "imperativo categórico" en un sentido analógico al empleado por Kant ${ }^{102}$. No obstante, con la negociación en el proceso penal se convierte a la norma de sanción en objeto de negociación entre el Fiscal y el acusado, y con ello se afecta el carácter de imperativo categórico como fundamento del sistema de justicia penal ${ }^{103}$, y se deja de lado la diferencia fundamental entre Derecho penal y Derecho civil ${ }^{104}$.

Si bien el Derecho penal recibe su legitimación a través de la protección de bienes jurídicos y en consecuencia, prima facie, cuando se consideran conductas delictivas que escapan a esa tarea, no estaría legitimado ${ }^{105}$; en los últimos años el concepto de bien jurídico se ha ampliado considerablemente con los delitos de peligro abstracto y otros tipos penales característicos de un Derecho penal moderno. Asimismo, muchas veces el legislador crea tipos penales que son únicamente medios de control social, que responden a las "exigencias punitivas" de la población, pero que no protegen bien jurídico alguno. Se está entonces ante bienes jurídicos aparentes ${ }^{106}$.

Desde esta perspectiva, el problema no reside sólo en la "ampliación" que el concepto de bien jurídico ha sufrido, sino en la tipificación de conductas sin referencia real a un bien jurídico. Incluso, en la doctrina penal, Roxin considera que, en el futuro limitar la intervención del Derecho penal a la protección de bienes jurídicos no va a satisfacer las exigencias de un Derecho penal moderno ${ }^{107}$.

100 FREUND, Georg, Strafrecht Allgemeiner Teil. Marburg: Springer, 1998, p. 1; KINDHÄUSER, Strafprozessrecht, cit. nota ${ }^{\circ} 12$, p. 47.

${ }^{101}$ KINDHÄUSER, Strafprozessrecht, cit. nota $\mathrm{n}^{\circ} 12$, p. 47.

${ }^{102}$ SCHÜNEMANN, Vom Tempel zum Marktplatz, cit. nota n ${ }^{\circ}$ 27, p. 16.

${ }^{103}$ SCHÜNEMANN, ,Strafrechtssystematisches Manifest“", cit. nota ${ }^{\circ}$ 89, p. 379.

${ }^{104}$ Sobre el carácter de imperativo categórico de la norma penal y las consecuencias de la justicia penal negociada en relación a esta característica. Sobre todo, SCHÜNEMANN, "Konsens im StrafverfahrenPerformativer Selbstwiderspruch", cit. nota n ${ }^{\circ} 21$, p. 55.

${ }^{105}$ GROPP. Strafrecht, cit. nota n ${ }^{\circ} 57$, p. 39.

${ }^{106}$ Sobre bienes jurídicos aparentes, HEFENDEHL, Roland, Kollektive Rechtsgüter im Strafrecht. Köln: Carl Heymanns, 2002, pp. 27 y ss.

${ }^{107}$ ROXIN, Strafrecht, cit. nota n ${ }^{\circ} 31$, p. 29. 
Polít. crim. Vol. 11, No 21 (Julio 2016), Art. 9, pp. 229-263.

[http://www.politicacriminal.cl/Vol_11/n_21/Vol11N21A9.pdf]

A fin de dar una primera respuesta a la cuestión de la posible legitimación de la negociación en el proceso penal, frente a los efectos que produce en el sistema penal (la alteración de la eficacia preventiva del Derecho penal y de la comunicación sobre el valor del bien jurídico), se exponen a continuación algunos puntos de vista doctrinales sobre dos calidades distintas de prevención general o dos grupos dentro del Derecho penal.

Al analizar la relación entre prevención general y derechos fundamentales, Naucke afirma que hay dos calidades de prevención general, que se distinguen en la calidad de la legitimación. Un primer ámbito concierne a la protección de la persona contra afectaciones personales dolosas y violentas de esa libertad, sería susceptible de fundamentar el merecimiento de pena y, por tanto, la prevención general sería legítima. Y considera, al mismo tiempo, apenas posible resolver la pregunta acerca del merecimiento de pena, de sanción y de la legitimación de la prevención fuera de ese ámbito nuclear ${ }^{108}$. En su opinión, es cuestionable seguir discutiendo sobre la prevención general sin dedicarse a las graduaciones o matizaciones de estas dos formas de Derecho penal ${ }^{109}$.

También Neumann afirma que, desde la teoría de la prevención general positiva (de la estabilización de la norma) es posible distinguir un núcleo central del Derecho penal (Kernbereich), en que los delitos efectivamente debiliten la confianza en la norma ${ }^{110}$. Y añade que, desde la teoría de la prevención general como confirmación de la norma lesionada, pueden tener lugar mecanismos de sustitución de la pena, como la reserva de fallo condenatorio y otros, como el acuerdo entre víctima y autor. Sin embargo, afirma que, en el caso de los delitos graves, la medida de la pena ha de expresarse en la medida de la desaprobación del delito ${ }^{111}$.

Según Roxin, la valoración de la prevención general y de la especial juegan distintos roles, según se trate de delitos graves o leves. En el primer caso, tendrá más relevancia la prevención general, por ello, la paz social sólo se alcanza cuando se sancione con un castigo adecuado a la culpa; y en el segundo, en cambio, se tomarán en consideración por encima de las necesidades preventivo-generales las exigencias preventivo-especiales del caso concreto. En este grupo de delitos podrían tendrían lugar instituciones como la conciliación, la libertad condicional y otras; puesto que se trata de delitos leves en los que la paz social sólo se ve afectada de forma leve ${ }^{112}$.

De acuerdo con la postura de Roxin, que considero de recibo, mientras más grave sea el delito, más obligatorio es, en virtud de la prevención general, agotar la medida de la culpa $^{113}$. De igual modo, aunque la culpa del autor es la medida de la pena máxima, la pena

\footnotetext{
108 NAUCKE, Wolfgang, "Generalprävention und Grundrechte der Person" en: HASSEMER, Winfried; LÜDERSSEN, Klaus; NAUCKE, Wolfgang, Hauptprobleme der Generalprävention, Frankfurt am Main: Alfred Metzner Verlag, 1979, pp. 27-28.

${ }^{109}$ NAUCKE, “Generalprävention”, cit. nota n 108, p. 28.

110 NEUMANN, Ulfrid, “Alternativen zum Strafrecht” en: NEUMANN, Ulfrid; PRITTWITZ, Cornelius (Eds.), Kritik und Rechtfertigung des Strafrechts. Frankfurt am Main: Peter Lang, 2005, p. 106.

${ }^{111}$ NEUMANN, "Alternativen”, cit. nota ${ }^{\circ} 110$, p. 107.

112 ROXIN, "Wandlungen", cit. nota n' 37, p. 712.

${ }^{113}$ ROXIN, "Wandlungen", cit. nota $\mathrm{n}^{\circ} 37$.
} 
HERRERA, Mercedes. "La negociación en el proceso penal desde la dogmática del Derecho penal. Especial referencia a los ordenamientos español y peruano".

puede estar por debajo de ésta, siempre que lo permita el fin preventivo de la pena ${ }^{114}$. Sostiene también que cuando exista un conflicto en cuanto a la pena que la prevención general y especial exige, se deben ponderar ambas y establecer una jerarquía. A las necesidades preventivo-especiales le corresponde la preferencia sólo en la medida que las exigencias mínimas de la prevención general estén garantizadas ("generalpräventiven Minimums"). Es decir, la pena no puede reducirse de tal modo que la sanción no sea tomada en serio en la población; ya que esto disminuiría la confianza en el ordenamiento jurídico $^{115}$.

En esta línea, Luzón Peña, aunque no habla de una "prevención general mínima" en su teoría de la prevención general de amenaza, llega a una conclusión semejante. Este autor vincula la prevención general a los principios de necesidad y eficacia, y postula que lo que basta para la intimidación debe bastar también para la tutela del Derecho ${ }^{116}$. Afirma también queel principio de necesidad obliga a comprobar si en el caso concreto y en todos los niveles de realización de la pena, su forma o su medida es realmente necesaria o no para que la función intimidatoria de la pena no experimente una disminución ${ }^{117}$. Con ello se evitaría caer en el terror penal, pero al mismo tiempo se podría determinar que los límites de las instituciones que tienden a la disminución, sustitución o suspensión de la pena pueden afectar la eficacia preventivo-general ${ }^{118}$.

Este autor considera también que los fines de la prevención general y especial deben armonizarse en la medida de lo posible, sobre todo cuando se trata de delitos leves. Y aquí deberá determinarse de modo estricto lo que es necesario para la prevención general y, en caso de conflicto, se debe dar preferencia a las exigencias preventivo-generales ${ }^{119}$. Ello significa que la prevención general prevalecerá cuando exista una absoluta incompatibilidad $^{120}$ entre las exigencias de la prevención general y especial. Así por ejemplo, frente a un delito leve la consideración de la prevención especial puede significar imponer una pena inferior a la gravedad del hecho porque es lo aconsejable desde la resocialización $^{121}$.

Sin tomar como base de su análisis la prevención general, Silva Sánchez y Lüderssen opinan que en el interior del Derecho penal coexisten distintos niveles, que pueden exigir una respuesta jurídico-penal y procesal también diversa.

\footnotetext{
${ }^{114}$ ROXIN, Strafrecht, cit. nota ${ }^{\circ} 31$, p. 93.

${ }^{115}$ ROXIN, Strafrecht, cit. nota $\mathrm{n}^{\circ} 31$, p. 87.

${ }^{116}$ LUZÓN PEÑA, Medición de la pena, cit. nota n 75, p. 35; LUZÓN PEÑA, "Generalprävention", cit. nota $\mathrm{n}^{\circ}$ 53, pp. 395-396.

117 LUZÓN PEÑA, “Generalprävention”, cit. nota n 53, p. 396.

${ }^{118}$ LUZÓN PEÑA, “Generalprävention”, cit. nota n 53, p. 397.

${ }^{119}$ LUZÓN PEÑA, Medición de la pena, cit. nota n 75, pp. 61 y ss.; LUZÓN PEÑA, “Generalprävention”, cit. nota $n^{\circ} 53$, pp. 397 y ss.

${ }^{120} \mathrm{Y}$ aquí estaría, según el propio Luzón Peña la diferencia con el punto de vista de Roxin en lo que concierne a la relación entre prevención general y especial. LUZÓN PEÑA, Medición de la pena, cit. nota $\mathrm{n}^{\circ} 75$, p. 63.

${ }^{121}$ LUZÓN PEÑA, Medición de la pena, cit. nota ${ }^{\circ} 75$, pp. 61 y ss.
} 
Polít. crim. Vol. 11, No 21 (Julio 2016), Art. 9, pp. 229-263.

[http://www.politicacriminal.cl/Vol_11/n_21/Vol11N21A9.pdf]

Al analizar la expansión del Derecho penal, Silva Sánchez, afirma que hoy en día es una realidad la coexistencia de "varios Derechos penales distintos" con estructuras típicas, reglas de imputación, principios procesales y sanciones sustancialmente distintas ${ }^{122}$. Propone adoptar un sistema penal de dos velocidades, es decir, con dos niveles de reglas de imputación, así como de garantías jurídico-penales y procesales, en función de si la pena a imponer es de prisión (especialmente penas de prisión de larga duración) o de otra clase. De tal modo que, en el nivel de penas privativas de libertad, se mantengan los presupuestos clásicos de imputación de responsabilidad ${ }^{123}$.

Por su parte, Lüderssen señala que dentro del bloque monolítico del Derecho penal concurren distintos fines particulares en función de las respuestas frente al injusto culpable ${ }^{124}$.Y afirma -en el contexto de un análisis de la negociación en el proceso penalque no todo tendría que ser negociable, porque una tal flexibilidad podría convertirse en arbitrariedad, y con la incertidumbre que la ampliación del consenso produce podría perderse lo que alguna vez se denominó pretensión penal pública ${ }^{125}$.

Silva Sánchez al proponer un "Derecho penal de dos velocidades”, apunta: “(...) De ahí que lo que sigue se sitúe ciertamente con alguna resignación, en una propuesta más realista, o si se quiere, posibilista acerca de la medida en que desde un Derecho penal con vocación racionalizadora, han de acogerse las demandas sociales de protección penal"126. La propuesta que a continuación se expone, expresa la necesidad de conciliar las necesidades prácticas con la doctrina jurídico-penal y procesal penal, ya que no se puede ignorar la realidad y seguir elucubrando teorías que ninguna repercusión tienen en la práctica $^{127}$.

De acuerdo con las anteriores consideraciones, no es un "imperativo categórico" aplicar al autor la pena merecida en todos los casos. En ese sentido, es legítimo un espacio procesal para instituciones procesales que, en aplicación de los principios de necesidad y eficacia de la pena, disminuyen la pena prevista en la amenaza penal. Sin embargo el límite de esta posibilidad debe ser el denominado "general-preventivo mínimo"128.

El Estado no está legitimado para perseguir la justicia por sí misma (es decir de forma exclusivamente retributiva), sólo tiene derecho y deber de castigar en la medida que sea necesario para la protección de los bienes jurídicos y, en esa medida, el Estado también debe retribuir la culpa ${ }^{129}$.

El Derecho penal cumple una función preventiva que admite graduaciones según se trate de delitos graves, de mediana gravedad, leves y de bagatela. Esta distinción responde también

\footnotetext{
122 SILVA SÁNCHEZ, La expansión del Derecho penal, cit. nota $\mathrm{n}^{\circ}$ 34, p. 175.

${ }^{123}$ Cfr. SILVA SÁNCHEZ, La expansión del Derecho penal, cit. nota $\mathrm{n}^{\circ} 34$.

${ }^{124}$ LÜDERSSEN, "Verständigung", cit. nota n 99, p. 440.

${ }^{125}$ LÜDERSSEN, "Verständigung", cit. nota n 99, p. 441.

${ }^{126}$ SILVA SÁNCHEZ, La expansión del Derecho penal, cit. nota n ${ }^{\circ} 34$, pp. 166-167.

127 Sobre esta necesidad SCHÜNEMANN, Bernd, "Kritik der Absprachen im Strafverfahren". Conferencia Belgrado: Manuscrito del autor, 2013, p. 13.

${ }^{128}$ ROXIN, Strafrecht, cit. nota ${ }^{\circ} 31$, p. 87.

129 SOUSA E BRITO, "Strafzwecke", cit. nota n 93, p. 317.
} 
HERRERA, Mercedes. "La negociación en el proceso penal desde la dogmática del Derecho penal. Especial referencia a los ordenamientos español y peruano".

al diferente valor de los "bienes jurídicos" que protege. La negociación en el proceso penal sólo puede legitimarse en los delitos en los que ese grado de pena no es preventivamente necesario y, por tanto, las partes están legitimadas en función de la prevención especial u otros criterios jurídico-penales a poner fin al conflicto jurídico-penal mediante un acuerdo. De tal suerte, que hay delitos en los que la imposición de la pena, de acuerdo con el mensaje transmitido con el anuncio de sanciones, resulta necesaria (irrenunciable) y el Estado está obligado a hacer uso del ius puniendi de acuerdo con los criterios establecidos por el Derecho penal; y otros, en los cuales se puede renunciar a la imposición de la pena inicialmente prevista, disminuirla o permitir que se atenúen las consecuencias jurídicopenales. Estos criterios se podrían desarrollar también desde el Derecho procesal penal.

En los delitos en los que la imposición de una pena adecuada a la culpa no resulta un "imperativo" se pueden admitir vías procesales como la negociación en el proceso penal sin lesionar significativamente la eficacia preventivo general del Derecho penal.

Dentro del Derecho penal se pueden identificar conductas de bagatela, delitos perseguibles a instancia de parte, delitos susceptibles de aplicación del principio de oportunidad y un núcleo de delitos que protegen bienes jurídicos fundamentales, como la vida o la libertad personal. En este último grupo se hace más patente que la eficacia de la función de protección de bienes jurídicos a través de la prevención general negativa requiere una sistemática funcional, lo que excluye la modificación de la norma de comportamiento a través de la dimensión procesal ${ }^{130}$.

En los delitos leves las necesidades de prevención especial pueden justificar tanto una renuncia a la pena, un archivo del proceso o una disminución de la pena. En cambio, en los delitos que afectan profundamente la confianza en el ordenamiento jurídico y perturban gravemente la paz social, la aplicación de los criterios jurídicos es de carácter obligatorio; puesto que, en los delitos graves, la potencia comunicativa de las normas penales sufre un detrimento cuando la sanción no se corresponde con la importancia del bien jurídico correspondiente $^{131}$.

No afirmo que cuando se trate de delitos leves la "calidad de la prevención general" justifica una manipulación de la pena concreta a imponer, sino que, en esos casos, se puede renunciar a la pena adecuada al hecho, al desvalor del injusto, sin que sea afectada profundamente la vigencia de la norma y la protección de bienes jurídicos. Si consideramos los delitos leves, el acuerdo entre la víctima y el autor puede satisfacer los fines de la pena o, por lo menos, no perjudicarla significativamente. Pero si se trata de delitos graves, la negociación en el proceso penal no realiza de modo suficiente las exigencias de la prevención general $^{132}$. Una disminución importante de pena significa necesariamente que la

\footnotetext{
${ }^{130}$ SCHÜNEMANN, ,Strafrechtssystematisches Manifest“, cit. nota ${ }^{\circ}{ }^{89}$, p. 379. Aunque este autor trata de la sistemática funcional de la norma de comportamiento en general, sin hacer distinción entre grupos de delitos.

131 SCHÜNEMANN, Bernd, "Pladöyer für eine neue Theorie der Strafzumessung", en: ESER, Albin; CORNILS, Karin (Eds.), Neuere Tendenzen der Kriminalpolitik. Beiträge zu einem deutsch-skandinavischen Strafrechtskolloquium. Friburgo: Max-Planck-Institut, 1987, p. 221.

${ }^{132}$ ROXIN, Strafrecht, cit. nota ${ }^{\circ} 31$, p. 90.
} 
Polít. crim. Vol. 11, No 21 (Julio 2016), Art. 9, pp. 229-263.

[http://www.politicacriminal.cl/Vol_11/n_21/Vol11N21A9.pdf]

medida de la pena no se corresponde con el injusto del hecho ${ }^{133}$. Aquí, volvemos a lo manifestado por Roxin: en los delitos graves la prevención general mínima exige que se apliquen las consecuencias jurídico-penales previstas. También puede verse desde la perspectiva del imputado o acusado, ya que los delitos graves están vinculados a penas privativas de libertad de larga duración, debe determinarse en un juicio oral, público y contradictorio, por medio de la verdad material su responsabilidad penal.

Ahora bien, determinar el núcleo de delitos en los que se puede permitir la negociación en el proceso penal de acuerdo con lo antes expuesto, exigiría un estudio más amplio, en el que entrarían en consideración la dogmática del Derecho penal, el Derecho de determinación de la pena (de discusión relativamente reciente en la dogmática alemana y española $)^{134}$, así como diversas circunstancias sociales y culturales que influyen en la valoración legislativa $^{135}$.

Volviendo a la reflexión sobre los delitos graves y leves, considero que aquellas conductas que son calificadas como delictivas por el legislador, pero cuya trascendencia no afecta significativamente a la comunidad jurídica, son susceptibles de procedimientos o vías procesales que permitan una rápida solución del conflicto que suscitan. Ahora bien, en estos casos, también es preciso que se tutelen los derechos del acusado y de la víctima, pero cabe legítimamente una protección menor de la que se otorga a los delitos más graves mediante el juicio oral. Esta exigencia viene impuesta por la propia función que cumple el Derecho penal en este tipo de delitos y no sólo por razones jurídico-procesales.

La autonomía del Derecho procesal penal está limitada por la propia función instrumental que cumple, es decir, por las exigencias del Derecho penal como sistema y ha de guiarse también en la creación de figuras y vías procesales- como el principio de oportunidad, la terminación anticipada, etc. por los principios y criterios jurídico-penales. (Protección del bien jurídico, prevención general positiva, etc.). Sobre este punto conviene traer a colación la teoría sobre la cuota última de sanción de $\mathrm{Zipf}^{136}$. Se trata de un planteamiento políticocriminal que se apoya también en la prevención general y se fundamenta en el principio de subsidiariedad.

\footnotetext{
${ }^{133}$ HÖRNLE, Tatjana, Tatproportionale Strafzumessung. Berlin: Duncker \& Humblot, 1999, p. 182.

${ }^{134}$ La doctrina de la "proporcionalidad del hecho" (Tatproportionalität) goza actualmente de gran aceptación en un sector de la doctrina. Esta doctrina fue introducida a la discusión alemana por SCHÜNEMANN. "Pladöyer für eine neue", cit. nota $\mathrm{n}^{\circ} 131$. Y posteriormente desarrollada por HÖRNLE. Tatproportionale, cit. nota $\mathrm{n}^{\circ}$ 33, pp. 126 y 388; ALBRECHT, Hans-Jörg. Strafzumessung bei schwerer Kriminalität. Berlin: Duncker \& Humblot, 1994. La discusión sobre esta teoría ha recibido un impulso en la doctrina penal alemana a través de la obra de VON HIRSCH, Andrew y JAREBORG, Nils, Strafmaß und Strafgerechtigkeit. Die deutsche Strafzumessungslehre und das Prinzip der Tatproportionalität. Forum, Bonn: Godesberg, 1991, pp. 11 y ss. También FRISCH, Wolfgang; VON HIRSCH, Andrew; ALBRECHT, Hans-Jörg. Tatproportionalität. Normative und empirische Aspekte einer Tatproportionalen Strafzumessung. Buchenbach-Symposium 1999. Heidelberg: C. F. Müller, 2003.

${ }^{135}$ Sobre este último punto VON HIRSCH/JAREBORG, Strafmaß und Strafgerechtigkeit, cit. nota n ${ }^{\circ} 134$, p. 45.

${ }^{136}$ ZIPF, Heinz, Kriminalpolitik. Ein Lehrbuch. $2^{\text {a }}$ ed., Heildeberg: C.F. Müller, 1980, p. 117.
} 
HERRERA, Mercedes. "La negociación en el proceso penal desde la dogmática del Derecho penal. Especial referencia a los ordenamientos español y peruano".

Según esta teoría, un exceso en el recurso al Derecho penal es perjudicial, porque con ello se debilita la fuerza preventiva del Derecho penal, puesto que hay un punto en el que el incremento de la sanción no contribuye a su vigencia, sino que por el contrario, debilita la misma. Así, las normas penales no deben pasar ciertos límites (problemas de la despenalización) y, al aplicar las sanciones se debe tener en cuenta una cuota de sanción óptima (optimale Sanktionierungsrate) ${ }^{137}$. De acuerdo con esta postura, el principio de subsidiariedad como instrumento de política criminal también se manifiesta en la preferencia de la sanción menor frente a otras más graves, cuando la primera sea suficiente. De ahí que frente a la pena privativa de libertad se prefiere la pena pecuniaria, frente a la pena completa se prefiere la suspensión condicional de la pena ${ }^{138}$.

Cuando se sanciona en exceso, la norma pierde su fuerza moral y, además, se pone de manifiesto que la norma no se cumple, lo que influye también en la generalidad ${ }^{139}$.En esta línea, Popitz ${ }^{140}$ ha defendido hace décadas la existencia de una präventive Wirkung des Nichtwissens. Según este autor, la eficacia preventivo-general del sistema depende también de que se mantenga cierta cifra oscura de criminalidad (Dunkelziffer) y de que la mayoría no reciba "lo que merece"; puesto que, si bien la vigencia de la norma de sanción es necesaria, el sistema sólo puede soportar una parte muy pequeña de esa vigencia ${ }^{141}$.

Si se relaciona la teoría de la cuota óptima de sanción con la negociación en el proceso penal, se advierte que el recurso a la negociación en el proceso penal se debe combinar con otros mecanismos de simplificación procesal (de manera similar a lo que ya ha ocurrido en Perú). Desde la óptica de la prevención general como fin de la pena, es posible esbozar una estructura procesal penal, que diversifica la reacción punitiva por niveles. En el primer nivel estaría la descriminalización de conductas de bagatela. A continuación, se sitúa la reparación y conciliación en determinados casos. Al principio de oportunidad le correspondería el tercer nivel. En el siguiente nivel se ubicaría la negociación en el proceso penal, que necesita una justificación adicional.

\section{Consideraciones de lege ferenda sobre la negociación en el proceso penal en los ordenamientos español y peruano.}

Después del analizar los efectos de la negociación en el proceso penal sobre la función del Derecho penal y el fin de la pena, expondré algunas consideraciones como balance general frente a todas las cuestiones antes tratadas y, presentaré algunas propuestas de lege ferenda para los ordenamientos procesales español y peruano.

Frente al estado actual de expansión del Derecho penal en los delitos leves, considero que la presunción de inocencia puede flexibilizarse en cuanto a la verdad material como exigencia frente a toda sentencia condenatoria, de tal suerte que, en los delitos leves, se

\footnotetext{
${ }^{137}$ ZIPF, Kriminalpoliti, cit. nota $\mathrm{n}^{\circ} 137$.

${ }^{138}$ ZIPF, Kriminalpoliti, cit. nota $\mathrm{n}^{\circ} 137$, pp. 52 y ss.

139 POPITZ, Heinrich, Über die Präventivwirkung des Nichtwissens. Tübingen: J.C.B. Mohr (Paul Siebeck), 1968 , pp. 15 y ss.

${ }^{140}$ POPITZ, Über die Präventivwirkung, cit. nota $\mathrm{n}^{\circ} 139$, p. 20.

${ }^{141}$ POPITZ, Über die Präventivwirkung, cit. nota $\mathrm{n}^{\circ} 139$.
} 
Polít. crim. Vol. 11, No 21 (Julio 2016), Art. 9, pp. 229-263.

[http://www.politicacriminal.cl/Vol_11/n_21/Vol11N21A9.pdf]

exija sólo la probabilidad de que hayan sido cometidos por el acusado. Sin embargo, también en este grupo de delitos se debe exigir que concurran suficientes indicios, actos de investigación, que funcionen como elementos de convicción, los mismos que deben ser controlados por el Juez.

Con esta propuesta no sugiero un cambio del statu quo de la negociación en el proceso penal en los ordenamientos español y peruano. Según se vio supra la negociación en el proceso penal supone una renuncia a la verdad material, en los términos en que ésta ha sido formulada por la doctrina procesal penal. La sentencia condenatoria se basa en indicios, elementos de convicción, pero no en pruebas (en Perú con la terminación anticipada se exigen "elementos de convicción suficientes": art. 468.6 Código Procesal Penal ("CPP”) de 2004), y el papel que asume el Juez es únicamente controlar que en efecto existe una probabilidad de que el delito concreto ha sido cometido por el acusado.

Cuando se trate de delitos graves, la presunción de inocencia exige que el Estado pruebe, exigiendo la certeza judicial, de que el acusado ha cometido un hecho típico antijurídico y culpable. La exigencia de certeza en los delitos graves también se relaciona con el Derecho penal (aunque la función de proteger los derechos del acusado se realiza en el proceso penal y, por ello, es propia de esta rama del Derecho), ya que través de la determinación de la verdad material se preserva la función del Derecho penal: protección de bienes jurídicos, a través de la prevención general negativa instrumental como fin intermedio de la pena. En este sentido, la verdad material es una exigencia de carácter procesal que, en última instancia, deriva del Derecho penal sustantivo. De ahí la importancia de que sea el Juez quien decida en el caso concreto la pena que corresponde aplicar y que resulte fundamental para este grupo de delitos mantener el juicio oral, mientras no haya un sucedáneo, otra vía a través de la cual se pueda establecer la verdad material.

Junto a la determinación de la verdad material el juicio oral sirve también al reconocimiento de la posición del acusado como sujeto procesal y permite, a través de la publicidad y oralidad, el control de la decisión judicial por la población. Pero, al mismo tiempo, satisface el interés de la generalidad al constatar que el delito recibe la pena que le corresponde $^{142}$.

La menor relevancia de los delitos leves se corresponde también con una menor exigencia en el nivel de la prueba. Así, si en los delitos más graves, es decir aquellos que afectan a bienes jurídicos fundamentales, la exigencia de certeza se deriva de la gravedad de los mismos y de la relación entre las ramas sustantiva y procesal, en los delitos leves, la exigencia de "indicios suficientes" es compatible con el desvalor de los delitos.

Sobre la propuesta según la cual la negociación en el proceso penal estaría permitida si durante la fase de investigación (Ermittlungsverfahren) el acusado ha tenido suficientes

\footnotetext{
${ }^{142}$ SCHÜNEMANN, "Kritik der Absprachen", cit. nota n 127, p. 6.
} 
HERRERA, Mercedes. "La negociación en el proceso penal desde la dogmática del Derecho penal. Especial referencia a los ordenamientos español y peruano".

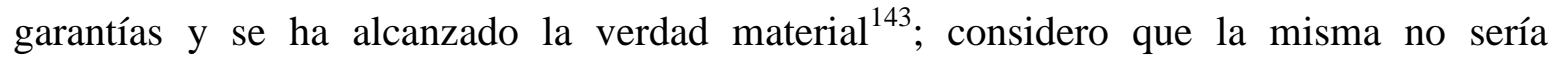
problemática cuando se trate de delitos leves. Sin embargo, al tratarse de delitos graves esta solución no resulta convincente, de una parte porque los actos de investigación no constituyen pruebas en sentido estricto. Si se aceptase una solución tal, se habría renunciado a la verdad material en los delitos graves de modo sistemático, al aceptar que en estos delitos el acusado y el Ministerio público pueden disponer parcialmente del proceso. Según lo expuesto supra, con esta renuncia se afecta a la prevención general como fin de la pena y a la función del Derecho penal.

En los delitos graves tampoco me parece convincente una mera limitación de la reducción de la pena (tal como establece el CPP peruano para todos los delitos), puesto que con ello se abdica de la pena merecida por el autor, la que corresponde al injusto y se acepta aquella que el Fiscal y el acusado proponen. En los delitos leves en cambio, sí tendría sentido una limitación de la reducción de la pena, sobre todo a fin de preservar la voluntariedad de la decisión del acusado de aceptar o negociar con el Fiscal. Si la reducción es excesiva se corre el peligro de que la negociación se convierta en un mecanismo "de aceptación automática", incluso cuando el acusado es inocente, pues probablemente le resulte más conveniente aceptar una pena que no merece, que acudir al juicio oral.

No obstante, en todo Estado de Derecho, la pena, aunque sea leve, no puede imponerse de cualquier modo. Por eso, en el grupo de delitos en los que se permita la negociación se deben establecer suficientes garantías en el proceso para a) preservar la libertad del acusado, de forma que no se vea sometido a presiones externas (del Juez, del Fiscal o incluso de la víctima), o a la presión del propio abogado, para decidirse a confesar su responsabilidad penal y acudir a la negociación en el proceso penal; b) exigir elementos de convicción suficientes; c) permitir que se pueda apelar la sentencia, no sólo cuando no se han cumplido los dos requisitos antes mencionados, sino también en defensa de la legalidad, cuando el tipo penal aplicado no se corresponde con los elementos de convicción (porque se trata de un hecho más grave o más leve), o cuando la pena está por debajo del mínimo legal. El art. 468 del CPP peruano prevé casi todos estos requisitos.

A fin de establecer la probabilidad de que el acusado haya cometido el delito, propongo una modificación del art. 468 del CPP peruano y del art. 446 (que regulan la terminación anticipada y el proceso inmediato respectivamente) en los siguientes términos: Se debe establecer un plazo tanto para la acumulación de elementos de convicción suficientes, como para su valoración. La práctica actual (por otra parte, permitida por ley) de aprobar acuerdos de terminación anticipada en tan sólo horas no facilita al Juez la toma de una decisión ponderada; pero sobre todo, impide al acusado y a la defensa valorar los indicios con los que se cuenta. Además, en un plazo tan corto el Fiscal tampoco ha podido tomar conocimiento a fondo de los hechos y del Derecho que corresponde aplicar, es decir de la pena.

\footnotetext{
${ }^{143}$ Así la propuesta de SCHÜNEMANN, Bernd, Wetterzeichen vom Untergang der deutschen Rechtskultur. Die Urteilabsprachen im Strafprozess als Abgesang auf die Gesetzesbindung der Justiz un den Beruf unserer Zeit zur Gesetzgebung. Berlin: Berliner Wissenschafts, 2005, pp. 30 y ss.
} 
Polít. crim. Vol. 11, No 21 (Julio 2016), Art. 9, pp. 229-263.

[http://www.politicacriminal.cl/Vol_11/n_21/Vol11N21A9.pdf]

Una terminación "acelerada" del proceso es, desde la óptica de la economía procesal, de gran ventaja para el Fiscal, el Juez y el acusado; pero es difícilmente conciliable con un Estado de Derecho. Incluso en casos de delito flagrante, tanto el acusado como el Fiscal necesitan tiempo para valorar los hechos de acuerdo con los elementos de convicción con los que se cuenta. Además, el acusado necesita tiempo para ejercer adecuadamente su derecho de defensa; en este caso, para hablar con su abogado, analizar detenidamente los hechos y los indicios con los que se cuentan y elaborar su estrategia de defensa. Y el Fiscal debe contar, asimismo, con el tiempo suficiente para decidir la pena que puede proponer según el Derecho y los indicios existentes.

La celeridad procesal no puede ser absolutizada. Su aplicación debe ser compatible con la toma de una decisión justa y que asegure la paz social; de lo contrario estaríamos frente a un proceso antijurídico ${ }^{144}$.

A fin de distinguir los delitos en los que se puede permitir la negociación en el proceso penal de aquellos en los que ésta se debe excluir, se podrían establecer tres grupos:

Al primer grupo pertenecerían los delitos que siempre se pueden considerar como graves; por ejemplo: el asesinato, las lesiones dolosas graves, el secuestro, la tortura, los atentados contra la indemnidad sexual de menores, el terrorismo. En ellos estaría excluida ex ante la negociación en el proceso penal.

En España, aunque la conformidad negociada se aplique según la Ley de Enjuiciamiento Criminal ("LECrim") sólo para delitos cuya pena concreta solicitada por la acusación no supere los seis años, con ello no se excluyen necesariamente los delitos graves, ya que el límite que impone la ley para la conformidad en el proceso abreviado se refiere a la pena concreta solicitada por la acusación. Basta que el MF formule acusación por una pena inferior a la que corresponde, por ejemplo por el extremo mínimo que contempla el Código Penal, para que proceda esta figura. Así, por ejemplo, en el delito de secuestro (art. 164), que prevé una pena privativa de libertad de 6 a 10 años. También el art. 177 bis Código Penal español que regula la trata de seres humanos, cuya pena es de 5 a 8 años de prisión.

Al segundo grupo pertenecerían los delitos en los cuales es necesaria una ponderación previa para determinar si, en el caso concreto, la negociación en el proceso penal estaría permitida. Según la intensidad de la afectación del bien jurídico y del elemento subjetivo, así como de otros factores que influyen en la determinación de la pena ${ }^{145}$. Para este fin, sería conveniente que una decisión de esta naturaleza esté a cargo de un funcionario independiente del Poder judicial y del Ministerio Público, que defienda los intereses generales. Su rol consistiría en decidir si se trata de un delito grave o leve a efectos de la posible aplicación de la terminación anticipada o conformidad negociada.

Ahora bien, esta determinación sería problemática, sobre todo en el ordenamiento procesal penal peruano; ya que los hechos concretos se fijan con el escrito de acusación y el art. 468

\footnotetext{
${ }^{144}$ GÖSSEL, „Quo Vadis, Strafverfahren?“, cit. nota ${ }^{\circ} 11$, pp. 502 y ss.

${ }^{145}$ SCHÜNEMANN, "Pladöyer für eine neue", cit. nota $n^{\circ} 131$, p. 227.
} 
HERRERA, Mercedes. "La negociación en el proceso penal desde la dogmática del Derecho penal. Especial referencia a los ordenamientos español y peruano".

inc.1 establece que la terminación anticipada tiene lugar después de emitida la disposición de formalización y continuación de la investigación preparatoria y antes de la acusación fiscal. En cambio, en España la conformidad negociada tiene lugar después de la acusación Art. 784. 3 LECrim y 787.1 (en este último caso la negociación tiene lugar en el juicio oral).

A fin de decidir si procede o no la negociación en el proceso penal, es decir, si en el caso concreto se trata de un delito grave o leve, hacen falta elementos de convicción suficientes. A este tenor, otra modificación del art. 468 del CPP que considero necesaria, es que la terminación anticipada tenga lugar después de la acusación fiscal. Pero esta disposición debe armonizarse con la modificación propuesta para el art. 446 y ss., que regulan el proceso inmediato; es decir, que en cualquier caso, debe establecerse un plazo para que tanto el Fiscal como el acusado puedan tomar una decisión ponderada.

Al tercer grupo pertenecen los delitos en los cuales la negociación en el proceso penal siempre estaría permitida por tratarse de delitos leves. Para esta clasificación también tiene especial importancia la "prevención general mínima", a la que antes se ha hecho referencia. Se podría considerar leve por ejemplo el delito de hurto. Aunque el bien jurídico patrimonio goza de reconocimiento constitucional, el conflicto puede ser solucionado de otro modo (por ejemplo a través de la negociación en el proceso penal), sin que con ello se vea afectada la confianza en la norma jurídica y en la protección que el patrimonio merece. En cambio, cuando concurran las agravantes que el art. 186 del Código Penal peruano prevé, y también en los hurtos cualificados que contempla el art. 235 del Código Penal español, tendría que valorarse si en el caso concreto procede la negociación en proceso pena. 
Polít. crim. Vol. 11, № 21 (Julio 2016), Art. 9, pp. 229-263.

[http://www.politicacriminal.cl/Vol_11/n_21/Vol11N21A9.pdf]

\section{BIBLIOGRAFÍA}

ALBRECHT, Hans-Jörg. Strafzumessung bei schwerer Kriminalität. Berlin: Duncker \& Humblot, 1994.

ALTENHEIN, Karsten; HAGEMEIER, Ina; HAIMERL, Michael; STAMMEN, Karl-Heinz, Die Praxis der Absprachen in Wirtschaftsstrafverfahren. Düsseldorf: Nomos, 2007.

ARMENTA DEU, Teresa (Coord.), La convergencia entre proceso civil y penal ¿una dirección adecuada?, Madrid: Marcial Pons, 2013.

BÖTTSCHER, Reinhard, „Der deutsche Juristentag und die Absprachen im Strafprozeß” en: ESSER, Albin; GOYDKE, Jürgen; RÜDIGER, Kurt. (Eds), Strafverfahrensrecht in Theorie und Praxis. Festschrift für Lutz Meyer-Gossner. München: C.H. Beck, 2001.

DEITERS, Mark, Legalitätsprinzip und Normgeltung. Tübingen:Mohr Siebeck, 2006.

DÖLLING, Dieter, „Generalprävention durch Strafrecht: Realität oder Illusion?“, Zeitschrift für die gesamte Strafrechtswissenschaft, vol. 102 (1990), pp. 3 y ss.

ERB, Volker, Legalität und Opportunität.Gegensätzliche Prinzipien der Andwendung von Strafrechtsnormen im Spiegel rechtstheoretischer, rechtsstaatlicher und rechtspolitischer Überlegungen, Berlin: Duncker \& Humblot, 1999.

FEIJOO SÁNCHEZ, Bernardo, "Positive Generalprävention,, en: PAWLIK, Michael; ZACZYK, Rainer (Eds.), FS für Günther Jakobs.Zum 70 Geburstag am 26 Juli 2007, Berlin: Carl Heymans, 2007, p. 86.

FEUERBACH, Anselm, Lehrbuch des gemeinen in Deutschland gültigen Peinlichen Rechts. Editado por Mittermaier, $14^{\circ}$ ed., aumentada, Giessen: Editorial Georg Friedrich, 1847.

FRISCH, Wolfgang; VON HIRSCH, Andrew; ALBRECHT, Hans-Jörg. Tatproportionalität. Normative und empirische Aspekte einer Tatproportionalen Strafzumessung. Buchenbach-Symposium 1999. Heidelberg: C. F. Müller, 2003.

GÖSSEL, Karl Heinz, „Quo Vadis, Strafverfahren? Zweckmäßigkeit versus Gerechtigkeit: Vom rechtsstaatlichen Strafprozess zum geheimen Willkürverfahren in der babylonischen Gefangenschaft der justiz“, Festeschrift für Gerhard Fezer zum 70 (2008), p. 499.

GRECO, Luis, Lebendiges und Totes in Feuerbachs Straftheorie. Ein Beitrag zur Gegenwärtigen strafrechtlichen Grundlagendiskussion. Berlin: Duncker \& Humblot, 2009.

GROPP, Walter, Strafrecht Allgemeiner Teil. $3^{\mathrm{a}}$ ed., Heildeberg: Springer, 2005.

GÜNTHER, Klaus, "Die Person der personalen Rechtsgutslehre“, en: NEUMANN, Ulfrid; PRITTWITZ, Cornelius (Eds.), Personale Rechtsgutslehre und „, Oferorientierung im Strafrecht“. Frankfurt am Maim: Peter Lang, 2007, p. 89.

HASSEMER, Winfried, „Prolegomena einer Lehre von der Zurechung“, en: SCHULZ, Joachim; VORMBAUM, Thomas (Eds.), FS für Günther Bemmann, Baden-Baden: Nomos, 1997, p. 187.

$382-383$. "Kennzeichen und Krisen des modernen Strafrechts", ZRP N 10 (1992), pp. Einführung in die Grundlagen des Strafrechts, $2^{\mathrm{a}}$ edición, Múnich: C.H Beck, 1990. 
HERRERA, Mercedes. "La negociación en el proceso penal desde la dogmática del Derecho penal. Especial referencia a los ordenamientos español y peruano".

HEFENDEHL, Roland, Kollektive Rechtsgüter im Strafrecht. Köln: Carl Heymanns, 2002. HÖRNLE, Tatjana, Straftheorien. Tübingen: Mohr Siebeck, 2011. , „Claus Roxins Straftheoretischer Ansatz“ en: HEINRICH, Manfred; JÄGER, Christian; ACHENBACH, Hans; AMELUNG, Knut; BOTTKE, Wilfried; HAFFKE, Bernhard; SCHÜNEMANN, Bernd; WOLTER, Jürgen (Eds.), Strafrecht als Scientia Universalis. FS für Claus Roxin zum 80. Geburtstag am 15. Mai 2011. Berlin: De Gruyter, 2011, p. 8.

, Tatproportionale Strafzumessung. Berlin: Duncker \& Humblot, 1999.

JAKOBS, Günther, Staatliche Strafe. Bedeutung und Zweck. Paderborn: Ferdinand Schöningh, 2004.

, Strafrecht Allgemeiner Teil. Die Grundlagen und die Zurechnungslehre. Berlin: De Gruyter, 1983.

JAKOBS, Günther; JESCHECK, Hans-Heinrich; WEIGEND, Thomas. Lehrbuch des Strafrechts. Allgemeiner Teil. Berlin: Duncker \& Humblot, 1996.

JUNG, Cornelia, Der Täter-Opfer-Ausgleich als Weisung. Verfahrensrechtliche Einwände und Auswege im Hinblick auf $\$ 153$ a. Abs. 1 StPO. Hamburg: Dr. Kovač, 2008.

KASPAR, Johannes, Wiedergutmachung und Mediation im Strafrecht. Rechtliche Grundlagen und Ergebnisse eines Modellprojekzs zur anwaltichen Schlichtung. Münster: Lid, 2004.

KAUFMANN, Armin, Die Aufgabe des Strafrechts. Düsseldorf: Westdeutscher Verlag, 1983.

KESPE, Hanschristian, Täter-Opfer-Ausgleich und Schadenswiedergutmachung. Ein Beitrag zur Dogmatik von $\$ 46^{a}$ StGB unter besonderer Berücksichtigung steuerstrafrechtlicher Fragestellungen. Berlín: Duncker \& Humblot, 2011.

KINDHÄUSER, Urs, Strafprozessrecht, $2^{\mathrm{a}}$ ed., Baden- Baden: Nomos, 2010.

KORIATH, Heinz, "Zum Streit um die positive Generalprävention-Eine Skizze" en: RADTKE, Henning; MÜLLER, Egon, et.al. (Eds.), Muss Strafe sein?, Baden-Baden: Nomos.

KUHLEN, Lothar, “Anmerkungen zur positive Generalprävention”, en: SCHÜNEMANN, Bernd; VON HIRSCH, Andrew; JAREBORG, Nils, (Eds.), Positive Generalprävention. Kritische Analysen im deutsch-englischen Dialog. UppsalaSymposium 1996, Heildeberg: C.F. Müller, 1998.

LÜDERSSEN, Klaus, "Verständigung im Strafverfahren. Das Modell uns seine Implikationen" en: MICHALKE, Regina; KIRSCH, Stefan (Eds.), Festschrift für Rainer Hamm sum 65. Geburstag am 24. Februar 2008. Berlin: De Gruyter Recht, pp. 419 y ss.

, Abschaffen des Strafens?. Frankfurt am Main: Suhrkamp, 1995.

LUZÓN PEÑA, Diego-Manuel, „Generalprävention, Gesellschaft und Psychoanalyse“, en: GA, Heidelberg: Decker's, 1984, pp. 396 y ss.

, Medición de la pena y sustitutivos penales. Madrid: Publicaciones del Instituto de Criminología de la Universidad Complutense de Madrid, 1979.

MIR PUIG, Santiago, Función de la pena y teoría del delito en el Estado social y democrático de Derecho. $2^{\mathrm{a}}$ ed., Barcelona: Bosch, 1982.

MONTERO AROCA, Juan, La prueba en el proceso civil, $5^{\mathrm{a}}$ ed., Pamplona: Aranzadi, 2007. 
Polít. crim. Vol. 11, № 21 (Julio 2016), Art. 9, pp. 229-263.

[http://www.politicacriminal.cl/Vol_11/n_21/Vol11N21A9.pdf]

MÜLLER-DIETZ, Heinz, "Integrationsprävention und Strafrecht. Zum positiven Aspekt der Generalprävention" en: VOGLER, Theo; HERMANN, Joachim; KRÜMPELMANN, Justus et. al. (Eds.), Festschrift für Hans-Heinrich Jescheck. Berlin: Duncker \& Humblot, 1985.

MÜLLER-TUCKFELD, Jens Christan, Integrationsprävention. Studien zu einer Theorie der gesellschaftlichen Funktion des Strafrechts. Peter Lang, 1997.

NAUCKE, Wolfgang, Die Wechselwirkung zwischen Strafziel und Verbrechensbegriff, Stuttgart: Franz Steiner, 1985.

,"Generalprävention und Grundrechte der Person" en: HASSEMER, Winfried; LÜDERSSEN, Klaus; NAUCKE, Wolfgang, Hauptprobleme der Generalprävention, Frankfurt am Main: Alfred Metzner Verlag, 1979.

NEUMANN, Ulfrid, "Alternativen zum Strafrecht” en: NEUMANN, Ulfrid; PRITTWITZ, Cornelius (Eds.), Kritik und Rechtfertigung des Strafrechts. Frankfurt am Main: Peter Lang, 2005.

NOLL, Peter, "Schuld und Prävention; Rationalisierung des Strafrechts" en: GEERDS, Friedrich; NAUCKE, Wolfgang (Eds.), FS für Hellmuth Mayer zum 70. Geburstag am 1. Mai 1965. Berlin: Duncker \& Humblot, 1966.

OLIVA SANTOS, Andrés de, El papel del Juez en el proceso civil. Frente a ideología, prudentia iuris. Pamplona: Thomson Reuters, 2012.

POPITZ, Heinrich, Über die Präventivwirkung des Nichtwissens. Tübingen: J.C.B. Mohr (Paul Siebeck), 1968.

POTT, Christine, Die Außerkraftsetzung der Legalitäts durch das Opportunitätsdenken in den Vorschriften der a StPO. Zugleich ein Beitrag zu einer kritischen Strafverfahrensrechtstheorie. Frankfurt am Main: Peter Lang, 1996.

ROXIN, Claus, "Wandlungen der Strafzwecklehre" en: Grunfragen staatlichen Strafens. FS für Heinz Müller-Dietz zum 70. Geburstag. Múnich: C.H. Beck, 2011, p. 701.

"Strafe und Strafzwecke in der Rechtsprechung des Bundesverfassungsgerichts" en: HASSEMER, Winfried; KEMPF, Ebehard; MOCCIA, Sergio (Eds.), In Dubio pro Libertate. FS für Klaus Volk zum 65. Geburtstag. Múnich: C.H. Beck, 2009, p. 611. , Strafrecht Algemeiner Teil. $4^{\mathrm{a}}$ ed., Múnich: Verlag C.H, 2006.

ROXIN, Claus; SCHÜNEMANN, Bernd, Strafverfahrensrecht. 27 edición, Múnich: Beck, 2012.

SCHEINFELD, Jörg, "Normschutz als Strafrechtsgut? Normentheoretische Überlegungen zum legitimen Strafen“, en: HEINRICH, Manfred; JÄGER, Christian; SCHÜNEMANN, Bernd; et. al. (Eds.), Strafrecht als Scientia Universalis. FS für Claus Roxin zum 80. Geburtstag am 15. Mai 2011.Vol. I, Berlin: De Gruyter, 2011, pp. 183 y ss.

SCHÖCH, Heinz, „Empirische Grundlagen der Generalprävention” en: VOGLER, Theo (Ed.), FS für Hans-Heinrich Jescheck zum 70. Geburtstag. Berlín: Duncker \& Humblot, 1985, pp. 1083 y ss.

SCHÜNEMANN, Bernd, Vom Tempel zum Marktplatz. Múnich: C.H. Beck, 2013.

, "Kritik der Absprachen im Strafverfahren". Conferencia Belgrado: Manuscrito del autor, 2013, p. 12. 
HERRERA, Mercedes. "La negociación en el proceso penal desde la dogmática del Derecho penal. Especial referencia a los ordenamientos español y peruano".

, „Reformaspekte des strafrechtlichen Haupt-und Rechtsmittelsverfahrens“, en: Die Reform des Haupt-und Rechtsmittelverfahrens. RichterInnenwoche 2010 in Geinberg 17.21 Mai 2010, Wien-Graz: Bundesministerium fürJustiz, 2011, p. 18.

, „Die Hauptverhandlung im Strafverfahren. Was sie leistet, wo sie versagt und in welcher Form sie bewahrt werden muss", Strafverteidiger forum, 2010, p. 91.

"Konsens im Strafverfahren-Performativer Selbstwiderspruch, Chimäre oder konkrete Utopie?" en: POSCH, Willibald; SCHLEIFER, Wolfgang; FERZ, Sascha (Eds.), Konfliktlösung im Konsens: Schiedgerichtsbarkeit, Diversion, Mediation. 7. Fakultätstag der Rehctswissenschaftlichen Fakultät der Karl-Franzes-Universität Graz, Graz: Leykam, 2010, p. 55.

"Zur Kritik des amerikanischen Strafprozessmodells". En: FS für Gerhard Fezer zum 70. Geburstag am 29. Oktober 2008. Berlin: De Gruyter Recht , 2008, p. 564 y ss.

, „Strafrechtssystematisches Manifest“, GA (2006), p. 379.

Wetterzeichen vom Untergang der deutschen Rechtskultur. Die Urteilabsprachen im Strafprozess als Abgesang auf die Gesetzesbindung der Justiz un den Beruf unserer Zeit zur Gesetzgebung. Berlín: Berliner Wissenschafts, 2005, p. $30 \mathrm{y}$ ss.

, “Wohin treibt der deutsche Strafprozess?”, ZStW 114 (2002), pp. 60 y ss.

"Zum Stellenwert der positiven Generalprävention in einer dualistischen Straftheorie", en: SCHÜNEMANN, Bernd; VON HIRSCH, Andrew; JAREBORG, Nils (Eds.), Positive Generalprävention. Kritische Analysen im deutsch-englischen Dialog. Uppsala-Symposium 1996, C.F. Heildeberg: Müller, 1998, p. 113.

, "Pladöyer für eine neue Theorie der Strafzumessung", en: ESER, Albin; CORNILS, Karin (Eds.), Neuere Tendenzen der Kriminalpolitik. Beiträge zu einem deutsch-skandinavischen Strafrechtskolloquium. Friburgo: Max-Planck-Institut, 1987, p. 221.

SILVA SÁNCHEZ, Jesús-María, La expansión del Derecho penal. Aspectos de la Política Criminal en las sociedades post-industriales. Montevideo-Buenos Aires: Editorial B de $\mathrm{f}, 2011$.

SOUSA E BRITO, José De, "Strafzwecke im Rechtsstaat" en: HERZOG, Felix; NEUMANN, Ulfrid (Eds.), FS für Winfried Hassemer zum 70. Geburstag am 17. Februar 2010. Heildeberg: C.F Müller, 2010, p. 308.

STRENG, Franz, "Die absolute Theorie als wahrer Kern der relativen Straftheorie?", en: HILGENDORF, Eric; RENGIER, Rudolf (Eds.), FS für Wolfgang Heinz. Zum 70. Geburtstag. Baden-Baden: Nomos, 2012, p. 679.

VON HIRSCH, Andrew; JAREBORG, Nils, Strafmaß und Strafgerechtigkeit. Die deutsche Strafzumessungslehre und das Prinzip der Tatproportionalität. Forum, Bonn: Godesberg, 1991.

WEIGEND, Thomas, Lehrbuch des Strafrechts. Allgemeiner Teil. Berlin: Duncker \& Humblot, 1996.

Absprachen in ausländischen Strafverfahren.Eine rechtsvergleichende Untersuchung zu konsensualen Elementen im Strafprozeß. Freiburg i.Br.: MaxPlanck-Institut für ausländisches und internationales Strafrecht, 1990. 
Polít. crim. Vol. 11, № 21 (Julio 2016), Art. 9, pp. 229-263.

[http://www.politicacriminal.cl/Vol_11/n_21/Vol11N21A9.pdf]

WOHLERS, Wolfgang, Deliktstypen des Präventionsstrafrechts. Zur Dogmatik modernen Gefährdungsdelikte. Berlin: Duncker \& Humblot, 2000.

WOLTER Jürgen; FREUND, Georg (Eds.), Straftat, Strafzumessung und Strafprozeß im gesamten Strafrechtssystem. Straftatbegriff, Straftatzurechnung, Strafrechtszweck, Strafausschluß, Strafverzicht, Strafklagverzicht. Heildeberg: Müller, 1996.

WOLTER, Jürgen, „Zur Theorie und Systematik des Strafprozessrechts. Nachschau und Ausblick“, en: WOLTER, Jürgen (Ed.), Zur Theorie und Systematik des Strafprozessrechts. Symposium zu Ehren von Hans-Joachim Rudolphi. Dortmund: Luchterhand, 1995, p. 268.

ZIPF, Heinz, Kriminalpolitik. Ein Lehrbuch. $2^{\mathrm{a}}$ ed., Heildeberg: C.F. Müller, 1980. , „Die verteidigung der Rechtsordnung” en: FURSCH, Wolfgang; SCHMID, Werner (Eds.), .FS für Hans-Jürgen Bruns zum 70. Geburstag. Lahn: Carl Heyman, 1978, p. 212. 